\title{
Density Functional Theory Study of Redox Potential Shifts in LixMnyFe1-yPO4 Battery Electrodes
}

\author{
Loftager, Simon; Schougaard, Steen Brian ; Vegge, Tejs; García Lastra, Juan Maria
}

Published in:

The Journal of Physical Chemistry Part C

Link to article, DOI:

10.1021/acs.jpcc.8b09167

Publication date:

2019

Document Version

Peer reviewed version

Link back to DTU Orbit

Citation (APA):

Loftager, S., Schougaard, S. B., Vegge, T., \& García Lastra, J. M. (2019). Density Functional Theory Study of Redox Potential Shifts in Li Mn Fe PO Battery Electrodes. The Journal of Physical Chemistry Part C, 123(1), 102-109. https://doi.org/10.1021/acs.jpcc.8b09167

\section{General rights}

Copyright and moral rights for the publications made accessible in the public portal are retained by the authors and/or other copyright owners and it is a condition of accessing publications that users recognise and abide by the legal requirements associated with these rights.

- Users may download and print one copy of any publication from the public portal for the purpose of private study or research.

- You may not further distribute the material or use it for any profit-making activity or commercial gain

- You may freely distribute the URL identifying the publication in the public portal 
Subscriber access provided by DTU Library

\section{C: Energy Conversion and Storage; Energy and Charge Transport}

\section{Density Functional Theory Study of Redox Potential Shifts in LiMnFePO Battery Electrodes}

Simon Loftager, Steen B. Schougaard, Tejs Vegge, and Juan María García-Lastra

J. Phys. Chem. C, Just Accepted Manuscript • DOI: 10.1021/acs.jpcc.8b09167 • Publication Date (Web): 07 Dec 2018

Downloaded from http://pubs.acs.org on December 8, 2018

\section{Just Accepted}

"Just Accepted" manuscripts have been peer-reviewed and accepted for publication. They are posted online prior to technical editing, formatting for publication and author proofing. The American Chemical Society provides "Just Accepted" as a service to the research community to expedite the dissemination of scientific material as soon as possible after acceptance. "Just Accepted" manuscripts appear in full in PDF format accompanied by an HTML abstract. "Just Accepted" manuscripts have been fully peer reviewed, but should not be considered the official version of record. They are citable by the Digital Object Identifier (DOI®). "Just Accepted" is an optional service offered to authors. Therefore, the "Just Accepted" Web site may not include all articles that will be published in the journal. After a manuscript is technically edited and formatted, it will be removed from the "Just Accepted" Web site and published as an ASAP article. Note that technical editing may introduce minor changes to the manuscript text and/or graphics which could affect content, and all legal disclaimers and ethical guidelines that apply to the journal pertain. ACS cannot be held responsible for errors or consequences arising from the use of information contained in these "Just Accepted" manuscripts. 


\begin{abstract}
Olivine-structured $\mathrm{LiMPO}_{4}$ materials (M = Mn, Fe, Co, Ni or mixtures) exhibit higher redoxpotentials than their layer oxide counteparts. This is due to the so-called inductive effect in the former where the inner P-O bonds in the phosphate units make the $\mathrm{M}-\mathrm{O}$ bond weaker than in the latter. A strategy to further increase the redox-potentials in the olivines is to mix two metals. Along these lines, Kobayashi et al. have shown experimentally that $\mathrm{Mn}^{2+}-\mathrm{Mn}^{3+}$ and $\mathrm{Fe}^{2+}-\mathrm{Fe}^{3+}$ redox potentials approximately shift $0.1 \mathrm{~V}$ upon full substitution of $\mathrm{Fe}$ by $\mathrm{Mn}$ in $\mathrm{Li}_{x} \mathrm{Mn}_{y} \mathrm{Fe}_{1-y} \mathrm{PO}_{4}$. Here, we found through Density Functional Theory calculations that the average metal-oxygen bond lengths $(\mathrm{M}=\mathrm{Mn}, \mathrm{Fe})$ increases upon rising $\mathrm{Mn}$ content, resulting in a decrease in the covalency of the transition-metal-oxygen interaction. The decrease in the covalency can be linked with good qualitative agreement to the experimentally observed $\mathrm{M}^{2+}-\mathrm{M}^{3+}$ voltage-plateau positive shift. Finally, the impact of the Mn-content-dependent voltage plateaus and unit-cell volume on the energy densities of the active compound is discussed.
\end{abstract}

\title{
1. INTRODUCTION
}

Lithium metal phosphates are attractive cathode materials due to their low cost, environmentally benign constituents and elevated redox potentials compared to their corresponding oxides. The improved potentials may be explained in crystal-field theory by the inductive effect exerted by phosphorus on oxygen within the phosphate group ${ }^{1}$. This entails a lower crystal-field splitting of the transition-metal d orbitals and thus a shift away from the $\mathrm{Li}-\mathrm{Li}^{+}$level of the counter electrode. $\mathrm{LiFePO}_{4}$, in particular, has been widely studied due to its excellent stability, although its voltage is limited $\left(\sim 3.4 \mathrm{~V} \mathrm{vs}\right.$. $\left.\mathrm{Li} / \mathrm{Li}^{+}\right)$when compared to other metal phosphates, such as $\mathrm{LiMnPO}_{4}\left(\sim 4.1 \mathrm{~V}\right.$ vs. $\left.\mathrm{Li} / \mathrm{Li}^{+}\right)$. By contrast, the chemical stability of $\mathrm{LiMnPO}_{4}$ has been shown to be inferior to that of $\mathrm{LiFePO}_{4}$. Additionally, the kinetics of delithiation-lithiation reaction for $\mathrm{LiMnPO}_{4}$ is considerably slower than $\mathrm{LiFePO}_{4}$, possibly due to structural instabilities of the Jahn-Teller-active $\mathrm{Mn}^{3+}$ phase ${ }^{2}$, lower intrinsic electronic and/or ionic conductivities $^{3,4}$, a larger lattice mismatch during the two-phase reactions ${ }^{3,5}$ and higher-lying surface states compared to the bulk energy states ${ }^{6}$. In an attempt to combine the high energy density of the $\mathrm{LiMnPO}_{4}$ cathode with the high stability of the $\mathrm{LiFePO}_{4}$ cathode, several groups have investigated 
mixed systems, i.e., $\mathrm{Li}_{x} \mathrm{Mn}_{y} \mathrm{Fe}_{1-y} \mathrm{PO}_{4}{ }^{7-9}$, which exhibit an $\mathrm{Fe}^{2+}-\mathrm{Fe}^{3+}$ voltage plateau when $\mathrm{x}<\mathrm{y}$ and a $\mathrm{Mn}^{2+}-\mathrm{Mn}^{3+}$ voltage plateau when $\mathrm{x}>\mathrm{y}$.

Interestingly, electrochemical charge-discharge experiments on $\mathrm{Li}_{x} \mathrm{Mn}_{y} \mathrm{Fe}_{1-y} \mathrm{PO}_{4}$ for $0 \leq x \leq 1$ (performed at a rate of $\mathrm{C} / 20$ at $30{ }^{\circ} \mathrm{C}$ ) conducted by Kobayashi et al. ${ }^{7}$ showed a systematic upshift of the $\mathrm{Fe}^{2+}-\mathrm{Fe}^{3+}$ redox potential as $\mathrm{Fe}$ in $\mathrm{LiFePO}_{4}$ was $\mathrm{Mn}$-substituted to form $\mathrm{LiMn}_{0.8} \mathrm{Fe}_{0.2} \mathrm{PO}_{4}$ and a systematic downshift of the $\mathrm{Mn}^{2+}-\mathrm{Mn}^{3+}$ redox potential as $\mathrm{Mn}$ in $\mathrm{LiMnPO}_{4}$ was Fe-substituted to form $\mathrm{LiMn}_{0.2} \mathrm{Fe}_{0.8} \mathrm{PO}_{4}$. Extrapolating their voltage-plateau data to the full Mn-content range, $0 \leq y \leq 1$, yields voltage shifts of $0.13 \mathrm{~V}$ and $0.16 \mathrm{~V}$ for the $\mathrm{Fe}^{2+}-\mathrm{Fe}^{3+}$ and $\mathrm{Mn}^{2+}-\mathrm{Mn}^{3+}$ voltage plateaus, respectively. In this paper, we seek to gain a deeper atomic-scale insight into the origin of these redox potential shifts and their practical implications on the cathode material.

The structure of this work is as follows. We first briefly introduce the basic structural properties of the olivine-structured lithium metal phosphates together with the computational methods used here, namely the density-functional theory (DFT). Thereafter, we present a DFT study of all possible configurations involving different $\mathrm{Li} / \mathrm{Mn} / \mathrm{Fe}$ and Li-valence electron arrangements in a $\mathrm{Li}_{x} \mathrm{Mn}_{y} \mathrm{Fe}_{1-y} \mathrm{PO}_{4}$ unit cell for $y=0,0.25,0.5,0.75,1$, imposing the constrain that the Li valence electrons localize on available $\mathrm{Mn}$ ion when $\mathrm{x}>\mathrm{y}$ (the $\mathrm{Mn}^{2+}-\mathrm{Mn}^{3+}$ plateau) and on available Fe ions when $\mathrm{x}<\mathrm{y}\left(\right.$ the $\mathrm{Fe}^{2+}-$ $\mathrm{Fe}^{3+}$ plateau.) As such, we first show that the origin of the aforementioned experimentally observed voltage shift stems from a change in the metal-oxygen bond lengths which again alters the energy of the metal:3d-oxygen:2p antibonding state. These bond-length changes are shown to be correlated to the $\mathrm{Mn} / \mathrm{Fe}$ ratio in the compound, and $\mathrm{M}-\mathrm{O}$ bond-length changes of $0.01 \AA$ in the $\mathrm{LiMPO}_{4}$ phase are observed. Lastly, the predicted convex-hull diagram of $\mathrm{Li}_{x} \mathrm{Mn}_{y} \mathrm{Fe}_{1-y} \mathrm{PO}_{4}$ with the resulting predicted open-circuit voltage (OCV) profiles is presented as well as the predicted gravimetric energy density (specific energy) and the volumetric energy density.

\section{METHODOLOGY}

2.1 Crystal structure of lithium metal phosphates $\left(\mathbf{L i}_{\mathbf{x}} \mathbf{M n}_{\mathbf{y}} \mathbf{F e}_{1-\mathbf{y}} \mathbf{P O}_{4}\right)$. Olivine $\mathrm{LiMPO}_{4}$ sets in the orthorhombic crystal system belonging to the Pnma space group (no. 60) and its unit cell contains four formula units of $\mathrm{LiMPO}_{4}$. See Figure S1 in Supporting Information for the olivine $\mathrm{LiMPO}_{4}$ structure with $\mathrm{M}=\mathrm{Fe}$. In this study, only $\mathrm{Mn}$ and Fe atoms are allowed to occupy the TM sites. The structure consists of sheets in the $b c$ plane of canted $\mathrm{MO}_{6}$ octahedra which are sharing corners with each other, while edge-sharing $\mathrm{LiO}_{6}$ octahedra run along the [010] direction. In this way, layers of $\mathrm{LiO}_{6}$ and $\mathrm{MO}_{6}$ octahedra each on a distorted 2D grid sequentially stack in the $a$ direction with a layer of $\mathrm{PO}_{4}$ units in between each metal-oxygen complex. $\mathrm{PO}_{4}$ units connect the $\mathrm{LiO}_{6}$ octahedra and the $\mathrm{MO}_{6}$ octahedra. 
For the input structure for the DFT calculations, the structure of Padhi et al. ${ }^{1}$ with specifications given in Table 1 was used. For the calculations on Mn-containing phases, relevant Fe ions were substituted by $\mathrm{Mn}$ and the structure was let to fully relax to its equilibrium state.

Table 1. Fractional coordinates and site symmetry of species in $\mathrm{LiFePO}_{4}$ in its Pnma space group ${ }^{10}$ used as the input structure for the DFT calculations. $a=10.334 \AA, b=6.008 \AA$ and $c=4.693 \AA$ were used as lattice constants ${ }^{1}$.

\begin{tabular}{|l|l|l|l|l|}
\hline Atom & $\boldsymbol{x}$ & $\boldsymbol{y}$ & $\boldsymbol{z}$ & Site symmetry \\
\hline $\mathrm{Li}$ & 0 & 0 & 0 & $-1(4 \mathrm{a})$ \\
\hline $\mathrm{Fe}$ & 0.28222 & 0.25 & 0.97472 & $\mathrm{~m} \mathrm{(4c)}$ \\
\hline $\mathrm{P}$ & 0.09678 & 0.25 & 0.41820 & $\mathrm{~m} \mathrm{(4c)}$ \\
\hline $\mathrm{O}(1)$ & 0.09678 & 0.25 & 0.74279 & $\mathrm{~m}(4 \mathrm{c})$ \\
\hline $\mathrm{O}(2)$ & 0.45710 & 0.25 & 0.20602 & $\mathrm{~m} \mathrm{(4c)}$ \\
\hline $\mathrm{O}(3)$ & 0.16558 & 0.25 & 0.28478 & $1(8 \mathrm{~d})$ \\
\hline
\end{tabular}

2.2 Computational methods. The initial structures for geometry relaxation were created and analyzed using the Atomic Simulation Environment (ASE) software package ${ }^{11}$. Subsequent optimization of ion positions and lattice parameters to their equilibrium state were achieved by solving the electronicstructure problem in density-functional theory (DFT) as implemented in the Vienna Ab initio Simulation Package (VASP) ${ }^{12}$. The Kohn-Sham one-electron valence states were expanded in a planewave basis using a kinetic-energy cutoff of $500 \mathrm{eV}$ and solved self-consistently using Pulay mixing ${ }^{13}$ of the electronic densities. The projector-augmented-wave (PAW) method ${ }^{14}$ was utilized to describe the atomic cores. As such Li and O 1s, P 1s, 2s, 2p, Mn as well as Fe, 1s, 2s, 2p, 3s and 3p electrons were treated as core electrons. The effects from exchange and correlation were modeled within the generalized-gradient approximation (GGA) using the Perdew-Burke-Ernzerhof (PBE) parametrization $^{15}$. Partial occupations were found by employing the Gaussian method, and the electronic levels were smeared by $10 \mathrm{meV}$. Due to the electronic self-interaction error, GGA results frequently give rise to noticeable deviations from experimental observations, especially of the band gap, ${ }^{16,17}$ which originates from the fact that the self-interaction tends to favor a delocalization of the electrons. This effect is particularly pronounced in systems with a strong localization of the d-orbital electrons, which is the case of the $\mathrm{Mn}$ and $\mathrm{Fe} 3 \mathrm{~d}$ orbitals in $\mathrm{Li}_{x} \mathrm{Mn}_{y} \mathrm{Fe}_{1-y} \mathrm{PO}_{4}$. Here, as well in previous studies $^{18-20}$, this problem is solved by utilizing the Hubbard- $U$ correction ${ }^{21}$. Following Zhou et al. ${ }^{18}$ a $U$ value of $4.5 \mathrm{eV}$ was applied on the $3 \mathrm{~d}$ orbitals of $\mathrm{Mn}$ and a $U$ value of $4.3 \mathrm{eV}$ was applied on the $3 \mathrm{~d}$ orbitals of Fe. Ferromagnetic spin arrangements were initialized on each TM ion (Mn and Fe) and all calculations were carried out with spin polarization. The nominal oxidation states of the TMs were determined by their magnetic moments as well as via their Bader charges ${ }^{22}$. The high-spin electronic configuration of $\mathrm{Fe}^{2+}$ yields a magnetic moment of $4 \mu_{\mathrm{B}}$ (four unpaired electrons) and $\mathrm{Fe}^{3+}$ one of $5 \mu_{\mathrm{B}}$ (five unpaired electrons), whereas $\mathrm{Mn}^{2+}$ and $\mathrm{Mn}^{3+}$ yield $5 \mu_{\mathrm{B}}$ and $4 \mu_{\mathrm{B}}$, respectively. 


\section{RESULTS AND DISCUSSION}

3.1 Voltage-plateau upshift upon Mn substitution. In order to investigate the shifting of the voltage plateaus observed by Kobayashi et al. ${ }^{7}$, we have used DFT calculations to determine the phase stability of $\mathrm{Li}_{x} \mathrm{FePO}_{4}$ and $\mathrm{Li}_{x} \mathrm{MnPO}_{4}$ and their mixed-metal phases, $\mathrm{Li}_{x} \mathrm{Mn}_{0.25} \mathrm{Fe}_{0.75} \mathrm{PO}_{4}, \mathrm{Li}_{x} \mathrm{Mn}_{0.5} \mathrm{Fe}_{0.5} \mathrm{PO}_{4}$ and $\mathrm{Li}_{x} \mathrm{Mn}_{0.75} \mathrm{Fe}_{0.25} \mathrm{PO}_{4}$ by calculating their convex hull. A total of 106 symmetry-inequivalent structures using a $\mathrm{Li}_{x} \mathrm{M}_{y} \mathrm{M}_{1-y} \mathrm{PO}_{4}(\mathrm{M} 1, \mathrm{M} 2=\mathrm{Mn}$ or Fe; $0 \leq x \leq 1)$ unit cell of four formula units (24 to 28 atoms) were investigated: 16 structures for $\mathrm{LiFePO}_{4}$ and $\mathrm{LiMnPO}_{4}$ each, 20 structures for $\mathrm{Li}_{x} \mathrm{Mn}_{0.25} \mathrm{Fe}_{0.75} \mathrm{PO}_{4}, 32$ structures for $\mathrm{Li}_{x} \mathrm{Mn}_{0.5} \mathrm{Fe}_{0.5} \mathrm{PO}_{4}$ and 22 structures for $\mathrm{Li}_{x} \mathrm{Mn}_{0.75} \mathrm{Fe}_{0.25} \mathrm{PO}_{4}$. These 106 configurations constitute the total number of possible symmetry-inequivalent configurations using the aforementioned unit cell of $\mathrm{Li}_{x} \mathrm{Mn}_{y} \mathrm{Fe}_{1-y} \mathrm{PO}_{4}$ including all degrees of freedom of the system, which are the following three, i) which Li sites are occupied, ii) how the $\mathrm{Mn}$ and $\mathrm{Fe}$ ions are distributed in the unit cell, and iii) the specific transition-metal ions in the cell that become oxidized upon the removal of $\mathrm{Li}$ ions from the structure. Here, we have assumed that the $\mathrm{Li}$ valence electrons localize on $\mathrm{Mn}$ ions (if they are present) until all $\mathrm{Mn}$ sites have been exhausted before they start to localize on Fe ions. From the total energies of these structures, $E_{\mathrm{Li}_{x} \mathrm{Mn}_{y} \mathrm{Fe}_{1-y} \mathrm{PO}_{4}}$, the relative energies were calculated using

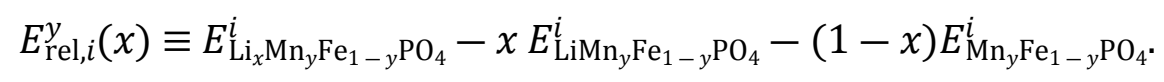

Equation 1

where $i$ runs over the symmetry-inequivalent configurations for fixed $x$ and $y$ values. Using the lowest of these relative energies for each $\mathrm{Li}$ concentration would yield the computationally predicted opencircuit voltage (OCV) of the system under strict equilibrium conditions at $\mathrm{T}=0 \mathrm{~K}$ with respect to a $\mathrm{Li}-$ metal reference electrode,

$$
U_{\mathrm{OCV}}^{y}(x)=\frac{E_{\mathrm{rel}}^{y}\left(x_{2}\right)-E_{\mathrm{rel}}^{y}\left(x_{1}\right)}{\left(x_{2}-x_{1}\right) e}+\frac{E_{\mathrm{LiMn}_{y} \mathrm{Fe}_{1-y} \mathrm{PO}_{4}}^{{ }_{2}}-\left(E_{\mathrm{Mn}_{y} \mathrm{Fe}_{1-y} \mathrm{PO}_{4}}+E_{\mathrm{Li}(\mathrm{s})}\right)}{e}, x_{1} \leq x \leq x_{2},
$$

Equation 2

with $e$ being the elementary charge. At finite temperatures, still under strict equilibrium, Equation 2 needs to be corrected using Boltzmann distribution to include the contributions from all the

configurations at a given $\mathrm{x}$ and $\mathrm{y} . \quad E_{\mathrm{B} o l t z m a n n}^{y} \mathrm{rel}(x)=\frac{\sum_{i} n_{i} e^{\frac{-E_{\mathrm{rel}, i}^{Y}(x)}{k_{B} T}} E_{\mathrm{rel}, i}(x)}{\sum_{i} n_{i} e^{\frac{-E_{\mathrm{rel}, i}^{y}(x)}{k_{B} T}}}$, 
where $E_{\text {rel, } i}^{y}$ is the relative energy defined in Equation $1, k_{\mathrm{B}}$ is Boltzmann constant, $\mathrm{T}$ is the temperature, and $n_{i}$ is the multiplicity of configuration $i$ (i.e. the number of symmetry-equivalent subconfigurations in configuration $i$ ).

The relative energies and $\mathrm{OCV}$ plots for the $\mathrm{Li}_{x} \mathrm{Mn}_{y} \mathrm{Fe}_{1-y} \mathrm{PO}_{4}$ system at $\mathrm{T}=0 \mathrm{~K}$ and $\mathrm{T}=300 \mathrm{~K}$ are shown in Figure 1. It should be noticed that the differences in the OCV plots at $\mathrm{T}=0 \mathrm{~K}$ and $\mathrm{T}=300$ are negligible.

a)
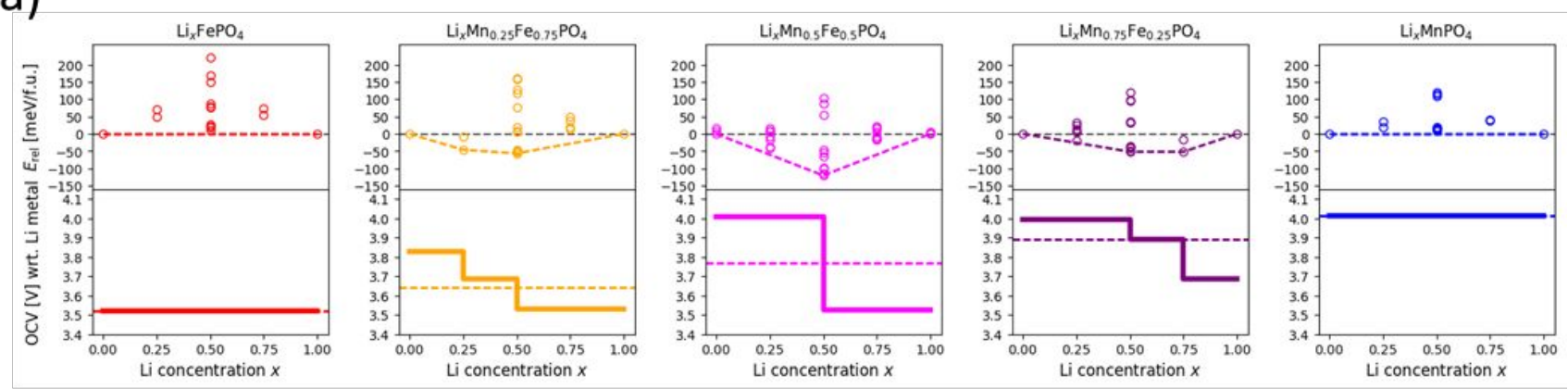

b)
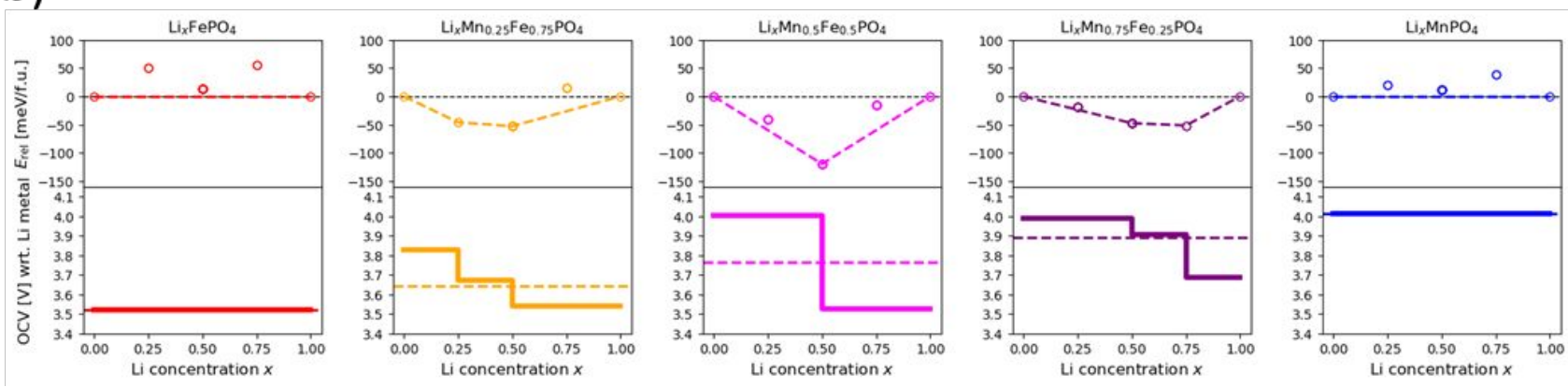

Figure 1. a) Phase-stability plots showing the relative energies and the convex hull using the lowest-lying energies with the associated open-circuit-voltage profiles for investigated ratios of $\mathrm{Fe}$ and $\mathrm{Mn}$. b) Phase-stability plots showing the relative energies and the convex hull using the Boltzmann averaged $(\mathrm{T}=300 \mathrm{~K})$ energies with the associated open-circuit-voltage profiles for investigated ratios of $\mathrm{Fe}$ and $\mathrm{Mn}$.

For $\mathrm{Li}_{x} \mathrm{FePO}_{4}, \mathrm{Li}_{x} \mathrm{Mn}_{0.5} \mathrm{Fe}_{0.5} \mathrm{PO}_{4}$ and $\mathrm{Li}_{x} \mathrm{MnPO}_{4}$ the convex hull is correctly predicted. However, for the $\mathrm{Li}_{x} \mathrm{Mn}_{0.25} \mathrm{Fe}_{0.75} \mathrm{PO}_{4}$ and $\mathrm{Li}_{x} \mathrm{Mn}_{0.75} \mathrm{Fe}_{0.25} \mathrm{PO}_{4}$ phases the convex hulls are not commensurate with the ones observed by Kobayashi ${ }^{7}$ and others, due to too stable configurations at half lithiation. Indeed, during operando conditions, kinetic effects will favor the presence of relative high-energy structures, whose contribution at equilibrium conditions would be otherwise insignificant. Estimating the likelihood of a given configuration including kinetic effects is not straightforward. To begin with, it would require to calculate all the transition state barriers between each possible couple of configurations at a given $\mathrm{x}$ and $\mathrm{y}$, which is a cumbersome task. The simplest approximation, followed here, is to consider that all the configurations at a given $\mathrm{x}$ and $\mathrm{y}$ have the same probability of occurrence. This approach is justified by the tortuous one-dimensional nature of Li diffusion in olivines, with relative high barriers for $\mathrm{Li}$ 
diffusion (between $0.6 \mathrm{eV}$ and $1.4 \mathrm{eV}$ in $\mathrm{LiFePO} 4$, depending on the degree of lithiation ${ }^{23}$ ). This tortuous $\mathrm{Li}$ diffusion in olivines suggests that in many cases the easiest way to move $\mathrm{Li}$ ions between two low energy configurations will be through a path that contains a relative high-energy configuration as an intermediate state. In this scenario, the transition state barriers, rather than the individual energy of each configuration determine the time that the system spends in each configuration. Therefore, we have calculated the average of the relative energies as each Li concentration for each $\mathrm{Fe}-\mathrm{Mn}$ composition as follows,

$$
E_{\text {avg rel }}^{y}(x)=\frac{\sum_{i} n_{i} E_{\text {rel }, i}^{y}(x)}{\sum_{i} n_{i}},
$$

An example of how these relative-energy averages are performed is found in the Supporting Information section S2. The associated OCV with respect to a $\mathrm{Li}$-metal reference electrode is calculated using

$$
U_{\mathrm{OCV}, \mathrm{avg}}^{y}(x)=\frac{E_{\mathrm{avg} \text { rel }}^{y}\left(x_{2}\right)-E_{\mathrm{avg} \text { rel }}^{y}\left(x_{1}\right)}{\left(x_{2}-x_{1}\right) e}+\frac{\left\langle E_{\mathrm{LiMn}_{y} \mathrm{Fe}_{1-y} \mathrm{PO}_{4}}^{y}\right\rangle-\left(\left\langle E_{\mathrm{Mn}_{y} \mathrm{Fe}_{1-y} \mathrm{PO}_{4}}^{y}\right\rangle+E_{\mathrm{Li}(\mathrm{s})}\right)}{e}, x_{1} \leq x \leq x_{2},
$$

Equation 5

where $\langle E\rangle$ denotes an average over the possible energies (for most Mn concentration, there is only one relative energy for $\mathrm{LiMn}_{y} \mathrm{Fe}_{1-y} \mathrm{PO}_{4}$ and $\mathrm{Mn}_{y} \mathrm{Fe}_{1-y} \mathrm{PO}_{4}$ ). The convex hull derived from these weighted relative energies is shown in Figure 2(a) with the associated OCV plot in (b). 


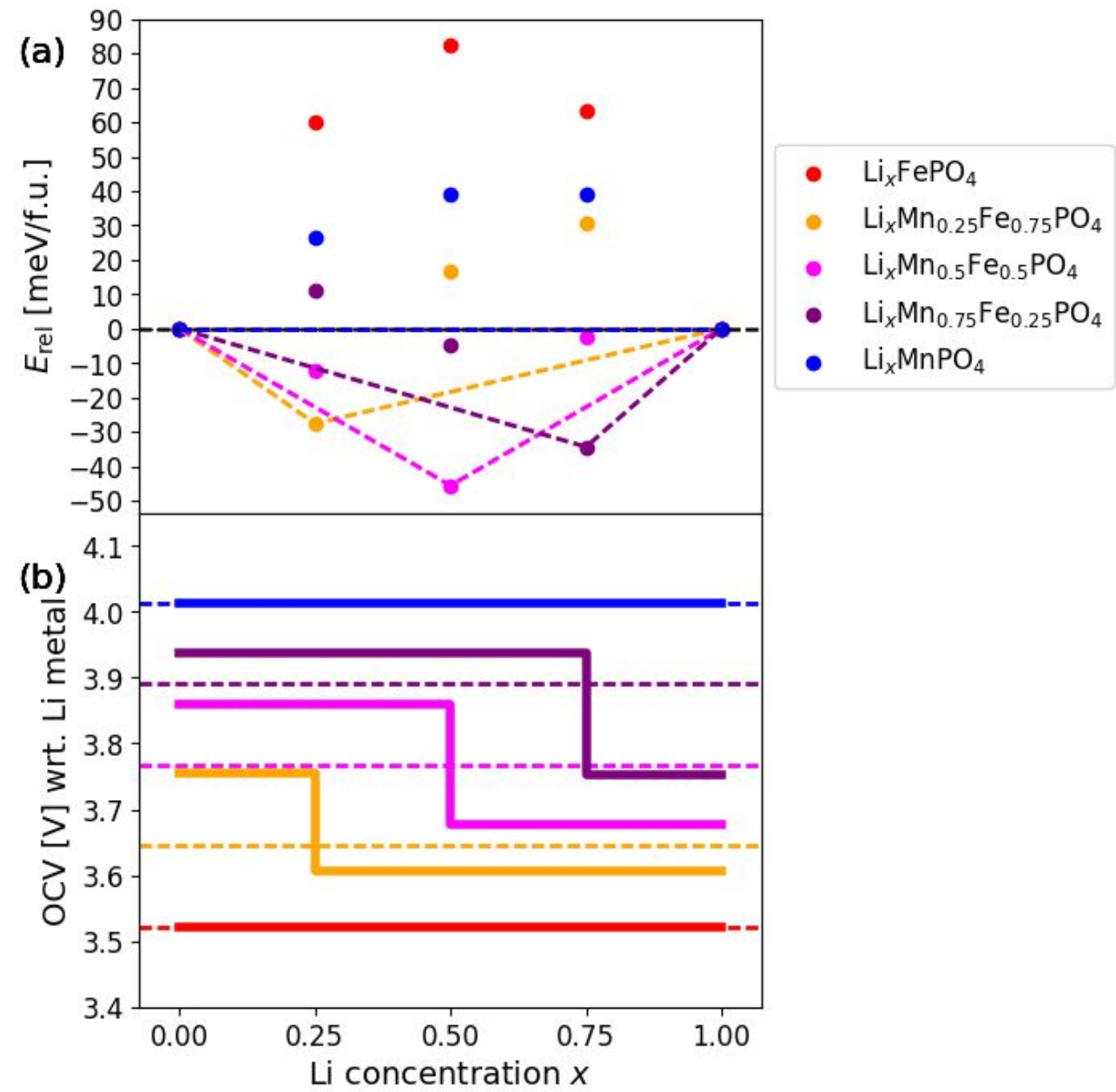

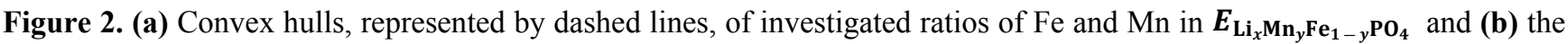
associated open-circuit voltage (OCV) showing how the redox couple plateaus increase upon Fe substitution by Mn. Equilibrium voltages are indicated by dashed horizontal lines. 


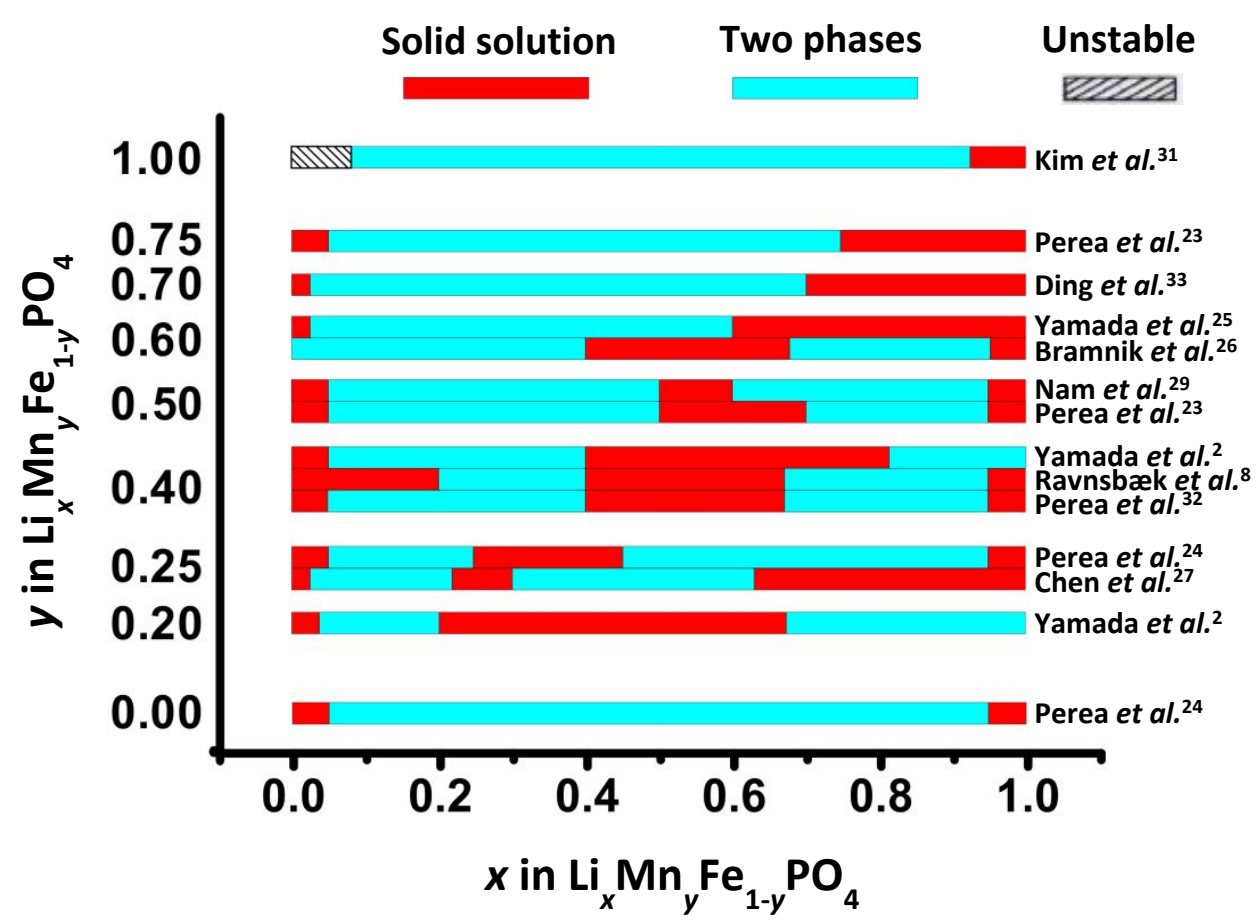

Figure 3. Overview of phases in $\mathrm{Li}_{x} \mathrm{Mn}_{y} \mathrm{Fe}_{1-y} \mathrm{PO}_{4}$ from previous experimental studies ${ }^{2,8,24-34}$. The data was taken from Trinh ${ }^{35}$.

As seen from the convex hull in Figure 2(a), there exist very stable phases at $x=y$ for all alloys (the solid-solution behavior around this place observed in experiments are not captured in the present DFT study, since our Li-concentration resolution is too low). These results agree well with experimental results summarized by Trinh et al. ${ }^{35}$ in Figure 3, where a solid-solution region, represented by red bars along $x=y$, separates the two-phase reactions (cyan bars) on both sides, one for the $\mathrm{Mn}^{2+}-\mathrm{Mn}^{3+}$ reaction $(x<y)$ and one for $\mathrm{Fe}^{2+}-\mathrm{Fe}^{3+}$ reaction $(x>y)$. As shown by Figure 2(b), the $\mathrm{Fe}^{2+}-\mathrm{Fe}^{3+}$ voltage plateau (four bottommost OCV profiles) increases as the Fe ions are substituted by $\mathrm{Mn}$ ions with a total plateau increase going from $\mathrm{Li}_{x} \mathrm{FePO}_{4}$ to $\mathrm{Li}_{x} \mathrm{Fe}_{0.25} \mathrm{Mn}_{0.75} \mathrm{PO}_{4}$ of $0.23 \mathrm{~V}$. Meanwhile, the $\mathrm{Mn}^{2+}-\mathrm{Mn}^{3+}$ voltage plateau (topmost $\mathrm{OCV}$ profiles) decreases as the $\mathrm{Mn}$ ions are substituted by $\mathrm{Fe}$ ions with a total increase going from $\mathrm{Li}_{x} \mathrm{MnPO}_{4}$ to $\mathrm{Li}_{x} \mathrm{Fe}_{0.75} \mathrm{Mn}_{0.25} \mathrm{PO}_{4}$ of $0.26 \mathrm{~V}$. Extrapolation of the voltage-plateau values, shown in Figure 4, to the full Mn-content range $(0 \leq y \leq 1)$ yields a total voltage shift of $0.34 \mathrm{~V}$ for the $\mathrm{Mn}^{2+}-\mathrm{Mn}^{3+}$ couple and $0.31 \mathrm{~V}$ for the $\mathrm{Fe}^{2+}-\mathrm{Fe}^{3+}$ couple. This agrees qualitatively well with the observations by Kobayashi et al. ${ }^{7}$ who reported a voltage-plateau upshift of $0.13 \mathrm{~V}$ and $0.16 \mathrm{~V}$ for the $\mathrm{Fe}^{2+}-\mathrm{Fe}^{3+}$ and $\mathrm{Mn}^{2+}-\mathrm{Mn}^{3+}$ plateaus, respectively, upon Mn-substituting $\mathrm{LiFePO}_{4}$ to $\mathrm{LiMnPO}_{4}$. Our results therefore predict a $\mathrm{Mn} / \mathrm{Fe}$ voltage upshift of 3.4/3.1 $\mathrm{mV}$ per percent $\mathrm{Mn}$ substituted for Fe. Kobayashi et al. ${ }^{7}$ and Snydacker et al. ${ }^{36}$ suggested that this voltage-plateau shift could be attributed to 
changes in the TM-O bond lengths, and we have therefore investigated the evolution of these bond lengths as the $\mathrm{Mn} / \mathrm{Fe}$ ratio is changed.

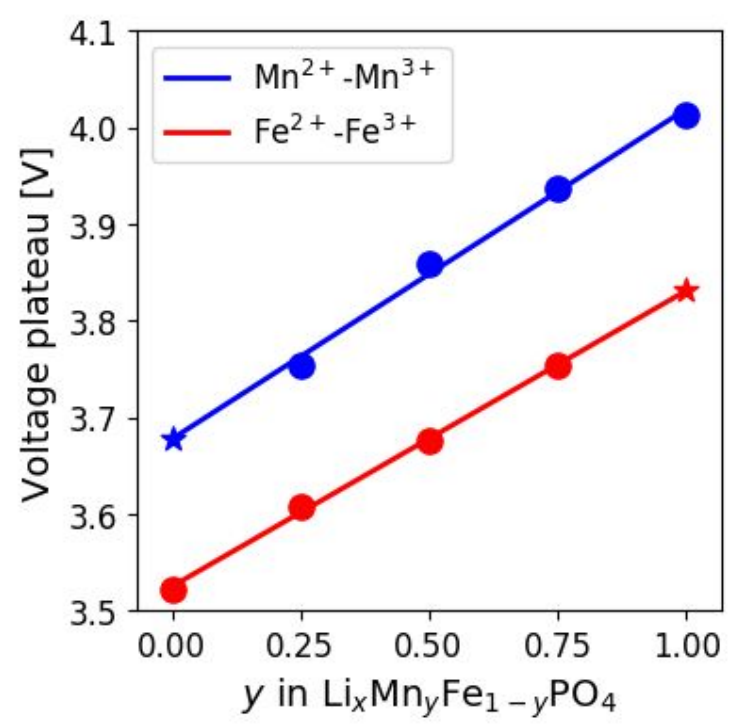

Figure 4. Calculated $\mathrm{TM}^{2+}-\mathrm{TM}^{3+}$ voltage plateau dependence on the Mn content $(y)$ in $\mathrm{Li}_{x} \mathrm{Mn}_{y} \mathrm{Fe}_{1-y} \mathrm{PO}_{4}$. The star data points are extrapolated from the dot data points obtained from the voltage plateaus in Figure 2(b).

3.2 Correlation of voltage-plateau shifts to structural changes. From Figure 5, a systematic small increase of $0.014 \AA$ in the multiplicity-weighted average $\mathrm{Fe}^{2+}-\mathrm{O}$ bond length in $\mathrm{LiMn}_{y} \mathrm{Fe}_{1-y} \mathrm{PO}_{4}$ (using extrapolation up to $y=1$ ) is obtained from the calculations as Fe ions are substituted by Mn ions. Due to the inductive effect ${ }^{1}$ this weakens the $\mathrm{Fe}-\mathrm{O}$ bonding, which strengthens the ionic character of $\mathrm{Fe}$, thereby lowering the $\mathrm{Fe}: 3 \mathrm{~d}-\mathrm{O}: 2 \mathrm{p}$ antibonding state, which results in a lowering of the $\mathrm{Fe}^{2+}-\mathrm{Fe}^{3+}$ redox energy leading to an increase in the OCV as suggested by Kobayashi et al. ${ }^{7}$ and illustrated in Figure 6. A similar argument holds for the downshift of the $\mathrm{Mn}^{2+}-\mathrm{Mn}^{3+}$ redox potential: A small decrease of $0.015 \AA$ in the average $\mathrm{Mn}^{2+}-\mathrm{O}$ bond lengths in $\mathrm{LiMn}_{y} \mathrm{Fe}_{1-y} \mathrm{PO}_{4}$ (using extrapolation down to $y=0$ ) is obtained from the calculations as Mn ions are substituted by Fe ions. Again, due to the inductive effect this strengthens the $\mathrm{Mn}-\mathrm{O}$ bonding, which enhances the ionic character of $\mathrm{Mn}$, thereby increasing the $\mathrm{Mn}: 3 \mathrm{~d}-\mathrm{O}: 2 \mathrm{p}$ antibonding state, which results in an increase of the $\mathrm{Mn}^{2+}-\mathrm{Mn}^{3+}$ redox energy leading to a decrease in the OCV of $\mathrm{Li}_{x} \mathrm{Mn}_{y} \mathrm{Fe}_{1-y} \mathrm{PO}_{4}$ upon Fe substitution. A similar, but significantly smaller increase $(0.006 \AA)$ in the average $\mathrm{Mn}^{3+}-\mathrm{O}$ bond length upon increasing Mn concentrations is also seen, whereas the average $\mathrm{Fe}^{3+}-\mathrm{O}$ bond length essentially remains constant.

It is well known that octahedral $\mathrm{Mn}^{3+}$ complexes exhibit strong pseudo-Jahn-Teller (JT) distortions in $\mathrm{Li}_{x} \mathrm{MnPO}_{4}$ compounds ${ }^{37,38}$ and the $\mathrm{Mn}_{y} \mathrm{Fe}_{1-y} \mathrm{PO}_{4}$ configurations in this study were therefore examined by calculating the measure of the degree of the JT distortion defined by, 


$$
d_{\mathrm{JT}} \equiv \frac{\sum_{i} b_{\mathrm{Mn}^{3+}-0}^{i}}{2}-\frac{\sum_{j} b \dot{\mathrm{Mn}}^{3+}-0}{4},
$$

where the first sum $(i)$ is over the two longest $\mathrm{Mn}^{3+}-\mathrm{O}$ bond lengths and the last sum $(j)$ in over the four shortest $\mathrm{Mn}^{3+}-\mathrm{O}$ bond lengths. Hence, a high (low) $d_{\mathrm{JT}}$ value indicates a large (small) pseudo-JT distortion of the $\mathrm{Mn}^{3+} \mathrm{O}_{6}$ complex. As seen by Figure 7, where the average of $d_{\mathrm{JT}}$ for each $\mathrm{Mn}$ concentration ( $y=0.5$ has three symmetry-inequivalent configurations) has been plotted, the degree of the JT distortion becomes more pronounced with higher Mn concentrations. The origin of this trend comes from the shorter $\mathrm{Fe}^{3+}-\mathrm{O}$ bond lengths compared to the $\mathrm{Mn}^{3+}-\mathrm{O}$ bond lengths, which effectively apply a compressive strain on the $\mathrm{Mn}^{3+}-\mathrm{O}$ bond lengths relative to the $\mathrm{Mn}^{3+}-\mathrm{O}$ bond lengths in the all$\mathrm{Mn}^{3+}$ phase $\left(\mathrm{MnPO}_{4}\right)$. Such a compressed $\mathrm{Mn}^{3+} \mathrm{O}_{6}$ complex cannot reach the same degree of pseudo-JT distortion (i.e., $d_{\mathrm{JT}}$ is relatively small) as a complex in an all- $\mathrm{Mn}^{3+}$ compound. This pseudo-JT distortion of the $\mathrm{Mn}^{3+} \mathrm{O}_{6}$ complexes constitutes a new mechanism which can alter the $\mathrm{Mn}^{2+}-\mathrm{Mn}^{3+}$ voltage plateau, and through that the OCV, in addition to the aforementioned metal-oxygen bondlength changes. As the pseudo-JT distortion increases so does the elastic energy required by the system to accommodate it. When the $\mathrm{Mn}^{3+}$ gets reduced to $\mathrm{Mn}^{2+}$ the pseudo-JT distortion disappears, recovering the elastic energy paid by the system. Thus, the larger the pseudo-JT distortion is, the more elastic energy is recovered upon lithiation, increasing the OCV. Typically, the JT stabilizations energies (equivalent to the elastic energy to accommodate the distortion) in $\mathrm{Mn}^{3+} \mathrm{O}^{2-}{ }_{6}$ complexes are around $0.25 \mathrm{eV} .{ }^{39}$ Assuming a linear relationship between the size of the distortion and the JT energies (i.e., following the harmonic approximation) passing from $d_{\mathrm{JT}}=0.43 \AA$ to $d_{\mathrm{JT}}=0.37 \AA$ would imply a change in the elastic energy of $\sim 0.03 \mathrm{eV}$. Even though this energy is rather small, it could explain why the shift in the OCV for the Fe plateau $(0.23 \mathrm{~V})$ is slightly smaller than that of Mn $(0.26 \mathrm{~V})$, although the change in the average metal-oxygen bond length was practically the same $(\sim 1.5 \mathrm{pm})$ in both cases. 


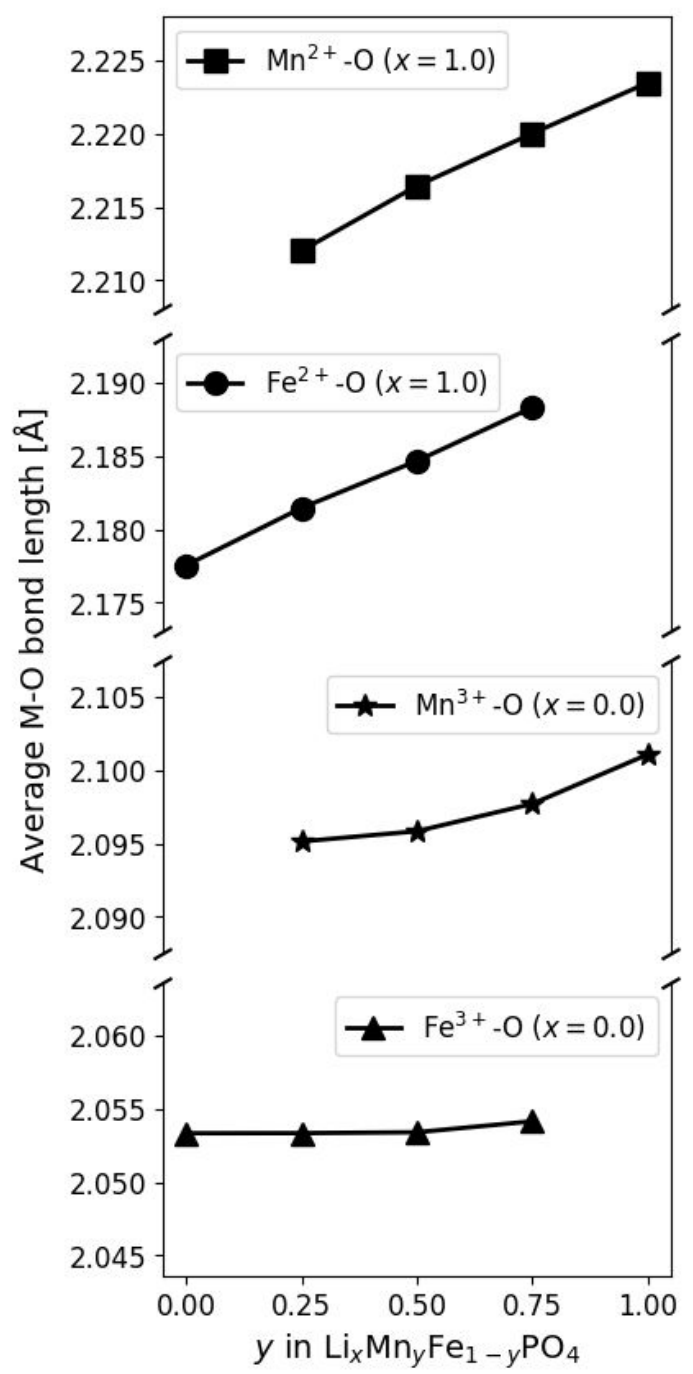

Figure 5. Average metal-oxygen bond lengths versus Mn concentration $y$ for both oxidation states $(2+$ and $3+)$ of Mn and Fe. 


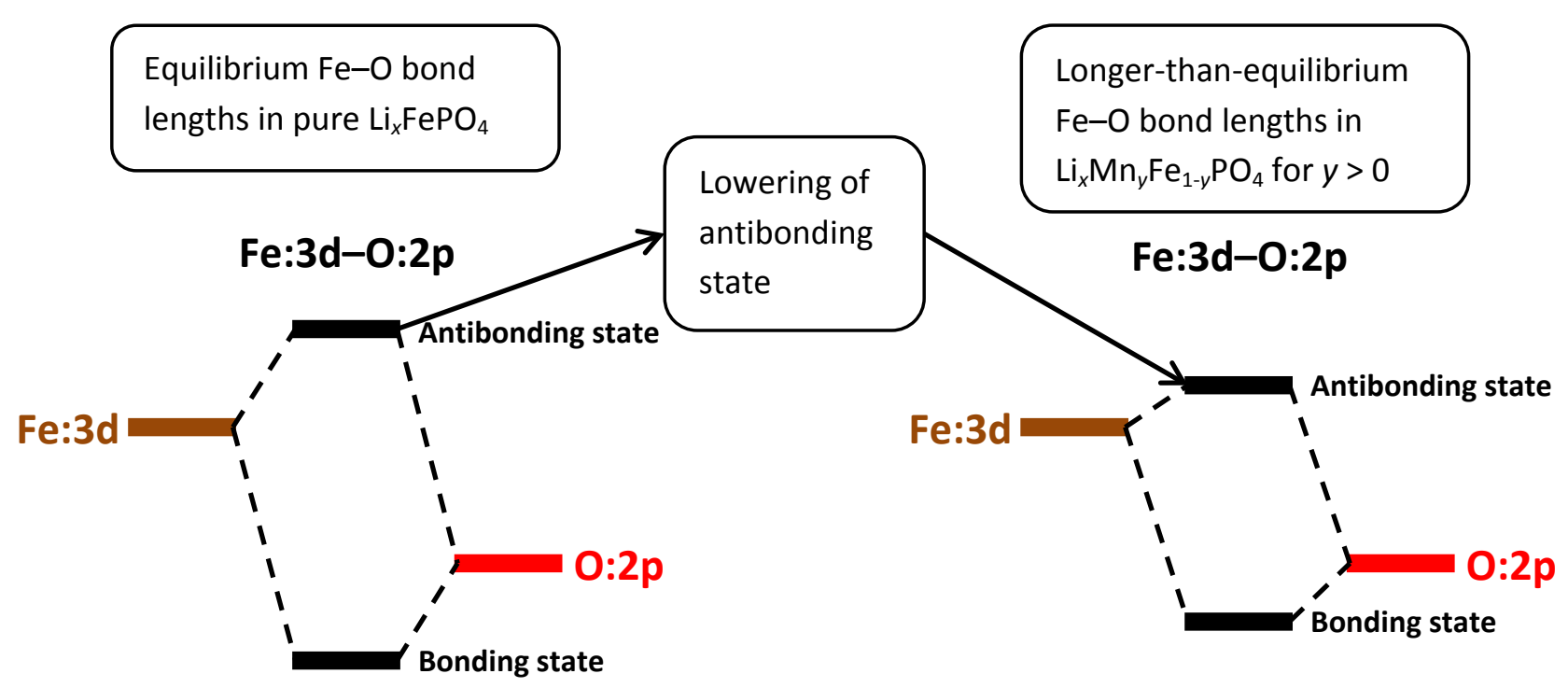

Figure 6. Origin of $\mathrm{Fe}^{2+}-\mathrm{Fe}^{3+}$ voltage-plateau upshift upon increasing $\mathrm{Mn}$ concentration: As $\mathrm{Fe}$ is substituted for Mn, the $\mathrm{Fe}-\mathrm{O}$ bond lengths increase (ultimately by $0.014 \AA$ on average from our calculations), thereby weakening the $\mathrm{Fe}-\mathrm{O}$ bonds. This lowers the antibonding state of the Fe:3d-O:2p mixing, lowering the redox potential and thereby increasing the OCV.

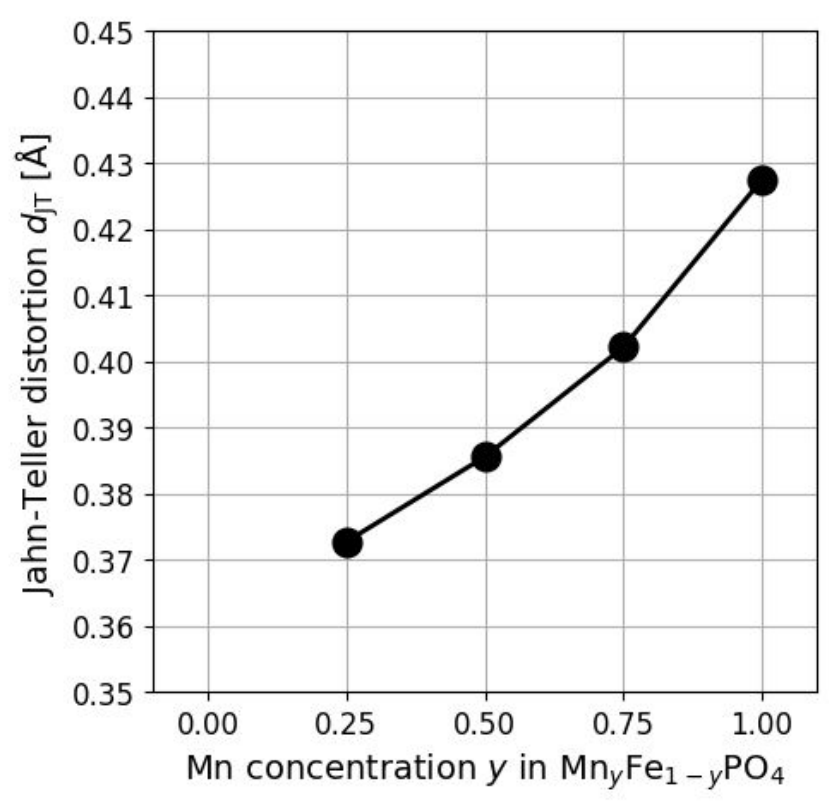

Figure 7. The average Jahn-Teller lattice distortion for each Mn concentration $y$ in $\mathrm{Mn}_{y} \mathrm{Fe}_{1-y} \mathrm{PO}_{4}$ configuration. 
3.3 Energy densities. In order to assess the influence of the voltage-plateau shifts on the energy densities, both the multiplicity-weighted averaged gravimetric energy density and the volumetric energy density of the active $\mathrm{Li}_{x} \mathrm{Mn}_{y} \mathrm{Fe}_{1-y} \mathrm{PO}_{4}$ material were calculated from our DFT results and these are plotted in Figure 8. A brief outline of how these energy densities are calculated is found in the Supporting Information section S3. Since the specific capacity of $\mathrm{LiMnPO}_{4}$ and $\mathrm{LiFePO}_{4}$ are very similar $(170.9 \mathrm{mAh} / \mathrm{g}$ and $169.9 \mathrm{mAh} / \mathrm{g}$, respectively), the main contribution to the associated gravimetric energy densities shown in Figure 8(a) stems from the linear $\mathrm{TM}^{2+}-\mathrm{TM}^{3+}$ redox voltage trends displayed in Figure 4, and since both the Mn and the Fe voltage plateaus increase by almost the same per Mn substituted for $\mathrm{Fe}$ (3.4 mV versus $3.1 \mathrm{mV}$ per percent $\mathrm{Mn}$ substituted for $\mathrm{Fe}$ for $\mathrm{Mn}^{2+}-$ $\mathrm{Mn}^{3+}$ and $\mathrm{Fe}^{2+}-\mathrm{Fe}^{3+}$ redox couples, respectively), the resulting gravimetric energy density also increases nearly linearly as a function of the Mn content $y$. A similar trend is seen for the volumetric energy density, defined as the total number of charges involved in the redox reactions in one unit cell multiplied by the voltage at which the reactions take place divided by the volume of the fully lithiated unit cell: A nearly linear increase in the energy density as the $\mathrm{Mn}$ content is increased. These values agree well with experiments (e.g., $2073 \mathrm{Wh} / \mathrm{L}$ for $\mathrm{LiFePO}_{4}$ and $2413 \mathrm{Wh} / \mathrm{L}$ for $\left.\mathrm{LiMnPO}_{4}\right)^{7,40}$.

However, the larger volume of the Mn-rich compounds compared to the Fe-rich compounds results in a slight negative curvature of the volumetric energy density versus the Mn content. In spite of the comparably smaller volume of the Fe-rich compounds combined with the upshift of the $\mathrm{Fe}^{2+}-\mathrm{Fe}^{3+}$ voltage plateaus (through $\mathrm{Mn}$ substitution), the volumetric energy density is still maximum for the $\mathrm{Li}_{x} \mathrm{MnPO}_{4}$ compound due to the significantly higher voltage of the $\mathrm{Mn}^{2+}-\mathrm{Mn}^{3+}$ redox process. 


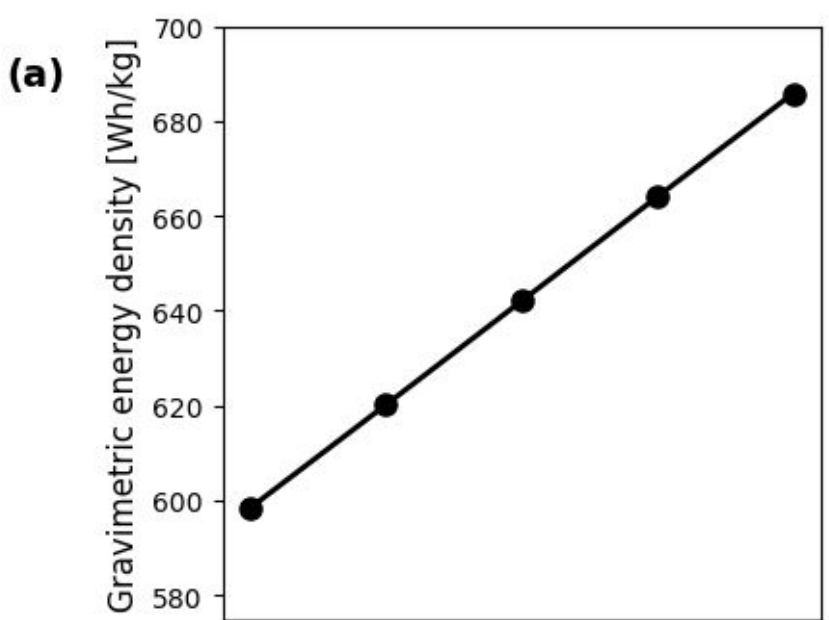

(b)

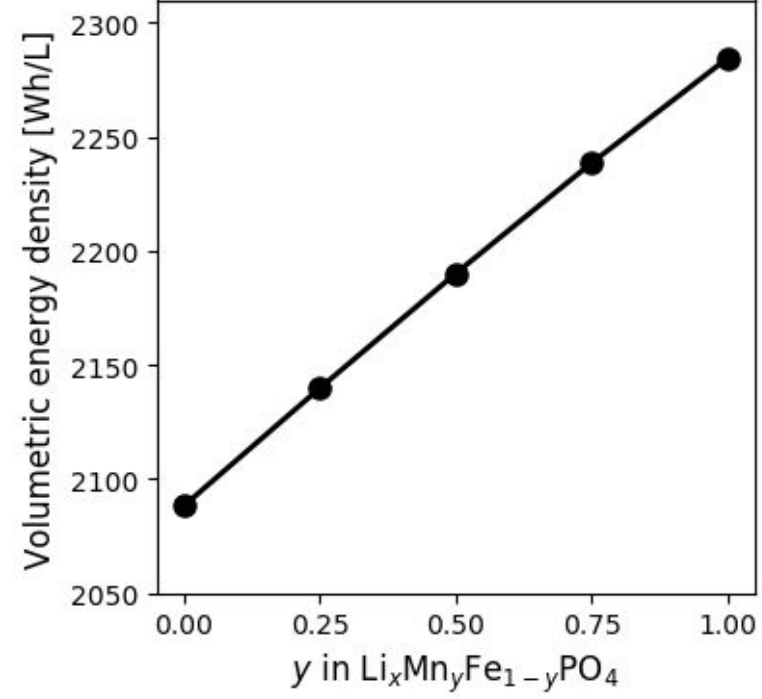

Figure 8. Gravimetric (a) and volumetric (b) energy densities versus the Mn content $y$. Both densities are for the active $\mathrm{Li}_{x} \mathrm{Mn}_{y} \mathrm{Fe}_{1-y} \mathrm{PO}_{4}$ material. The volumetric density is calculated using the volume of the fully lithiated unit cells.

\section{CONCLUSIONS}

The benefits of the high average voltage from $\mathrm{Mn}$, the excellent stability from $\mathrm{Fe}$ and the good rate capability of the mixed-metal compound ${ }^{9}$, combined with the inexpensive $\mathrm{PO}_{4}$ anionic framework of $\mathrm{Li}_{x} \mathrm{Mn}_{y} \mathrm{Fe}_{1-y} \mathrm{PO}_{4}(0 \leq x \leq 1$ and $0 \leq y \leq 1)$ makes this material very attractive for use as a Li-ion cathode resulting in numerous studies of the lithiated mixed-metal olivine phosphates ${ }^{7-9}$. However, this cathode material still raises some fundamental questions, one of them being why the voltage plateaus of the transition-metal (TM) redox couples change as a function of the Mn content (y) as observed in experiments ${ }^{7}$. Through a careful density-functional-theory (DFT) study of each Li-TM arrangement and Li-valence-electron localization arrangement in one unit cell of $\mathrm{Li}_{x} \mathrm{Mn}_{y} \mathrm{Fe}_{1-y} \mathrm{PO}_{4}$ (4 f.u.), we have 
found this voltage-plateau upshift upon increasing the $\mathrm{Mn} / \mathrm{Fe}$ ratio to originate from the TM-O bondlength changes as the average TM-O bond lengths increases (by $0.015 \AA$ for the $\mathrm{Mn}^{2+}-\mathrm{O}$ bond lengths and $0.014 \AA$ for the $\mathrm{Fe}^{2+}-\mathrm{O}$ bond lengths). These bond-length changes alter the TM:3d-O:2p antibonding state such that this is lowered (raised) for Fe (Mn), thereby increasing (decreasing) the open-circuit voltage upon increasing (decreasing) $\mathrm{Mn} / \mathrm{Fe}$ ratio. Additionally, we found that the strength of the pseudo-Jahn-Teller distortion in the $\mathrm{Mn}^{3+} \mathrm{O}^{2-}{ }_{6}$ complexes increased upon increasing $\mathrm{Mn}$ concentration, which we think could have an impact on the open-circuit voltage in addition to the above-mentioned TM-O bond-length effects.

Notably, we found that it was crucial to perform an averaging over the relative energies at each $\mathrm{Li}$ concentration and $\mathrm{Mn}$ concentration instead of following the conventional approach of using the lowest-lying relative energies at each $x$ and $y$. In this way, excellent agreement with experimental results were obtained. This points out the importance of including higher-energy configurations, which unavoidably will be present during the charge and discharge cycling of the cathode materials.

A consequence of the Mn-content-dependent voltage is a potential nontrivial dependence of the energy densities upon the Mn content, in particular regarding the volumetric energy density since the volume also depends on the Mn content. However, our studies found a nearly linear trend for both the gravimetric and the volumetric densities, favoring a Mn-rich compound if the energy densities were to be maximized.

\section{ASSOCIATED CONTENT}

\section{Supporting Information}

Crystal structure of $\mathrm{LiFePO}_{4}$; weighted relative energies via symmetry-equivalent subconfigurations; energy densities.

\section{AUTHOR INFORMATION}

\section{Corresponding Author}

*E-mail: jmgla@dtu.dk. Tel: +45 45258213

\section{Notes}

The authors declare no competing financial interest.

\section{ACKNOWLEDGEMENTS}


JMGL acknowledges support from the Villum Foundation's Young Investigator Programme ( $4^{\text {th }}$ round, project: In silico design of efficient materials for next generation batteries. Grant number: 10096).

SBS acknowledges support from UQAM, including funding for his sabbatical at DTU.

\section{REFERENCES}

(1) Padhi, A. K. Phospho-Olivines as Positive-Electrode Materials for Rechargeable Lithium Batteries. J. Electrochem. Soc. 1997, 144 (4), 1188. https://doi.org/10.1149/1.1837571.

(2) Yamada, A.; Kudo, Y.; Liu, K.-Y. Phase Diagram of $\mathrm{Li}_{x}\left(\mathrm{Mn}_{y} \mathrm{Fe}_{1-y}\right) \mathrm{PO}_{4}(0 \leq x, y \leq 1) . J$. Electrochem. Soc. 2001, 148 (10), A1153-A1158. https://doi.org/10.1149/1.1401083.

(3) Yonemura, M.; Yamada, A.; Takei, Y.; Sonoyama, N.; Kanno, R. Comparative Kinetic Study of Olivine $\mathrm{Li}_{x} \mathrm{MPO}_{4}(\mathrm{M}=\mathrm{Fe}, \mathrm{Mn})$. J. Electrochem. Soc. 2004, 151 (9), A1352-A1356. https://doi.org/10.1149/1.1773731.

(4) Delacourt, C.; Laffont, L.; Bouchet, R.; Wurm, C.; Leriche, J.; Morcrette, M.; Tarascon, J.-M.; Masquelier, C. Toward Understanding of Electrical Limitations (Electronic, Ionic) in $\mathrm{LiMPO}_{4}$ ( $\mathrm{M}=\mathrm{Fe}, \mathrm{Mn})$ Electrode Materials. J. Electrochem. Soc. 2005, 152 (5), A913-A921. https://doi.org/10.1149/1.1884787.

(5) Meethong, N.; Huang, H. Y. S.; Speakman, S. A.; Carter, W. C.; Chiang, Y. M. Strain Accommodation during Phase Transformations in Olivine-Based Cathodes as a Materials Selection Criterion for High-Power Rechargeable Batteries. Adv. Funct. Mater. 2007, 17 (7), 1115-1123. https://doi.org/10.1002/adfm.200600938.

(6) Wang, L.; Zhou, F.; Ceder, G. Ab Initio Study of the Surface Properties and Nanoscale Effects of $\mathrm{LiMnPO}_{4}$. Electrochem. Solid-State Lett. 2008, 11 (6), A94-A96. https://doi.org/10.1149/1.2901974.

(7) Kobayashi, G.; Yamada, A.; Nishimura, S.; Kanno, R.; Kobayashi, Y.; Seki, S.; Ohno, Y.; Miyashiro, H. Shift of Redox Potential and Kinetics in $\mathrm{Li}_{x}\left(\mathrm{Mn}_{y} \mathrm{Fe}_{1-y}\right)$ PO $\mathrm{P}_{4}$. J. Power Sources 2009, 189 (1), 397-401. https://doi.org/10.1016/j.jpowsour.2008.07.085.

(8) Ravnsbæk, D. B.; Xiang, K.; Xing, W.; Borkiewicz, O. J.; Wiaderek, K. M.; Gionet, P.; Chapman, K. W.; Chupas, P. J.; Tang, M.; Chiang, Y. Engineering the Transformation Strain in $\mathrm{LiMn}_{y} \mathrm{Fe}_{1-y} \mathrm{PO}_{4}$ Olivines for Ultrahigh Rate Battery Cathodes. Nano Lett. 2016, 16 (4), 23752380. https://doi.org/10.1021/acs.nanolett.5b05146.

(9) Oh, S.-M.; Myung, S.-T.; Choi, Y. S.; Oh, K. H.; Sun, Y.-K. Co-Precipitation Synthesis of Micro-Sized Spherical $\mathrm{LiMn}_{0.5} \mathrm{Fe}_{0.5} \mathrm{PO}_{4}$ Cathode Material for Lithium Batteries. J. Mater. Chem. 2011, 21 (48), 19368. https://doi.org/10.1039/c1jm13889h.

(10) Abu-Lebdeh, Y.; Davidson, I. Nanotechnology for Lithium-Ion Batteries; Lockwood, D. J., Ed.; 
Springer, 2013.

(11) Larsen, A.; Mortensen, J.; Blomqvist, J.; Castelli, I.; Christensen, R.; Dulak, M.; Friis, J.; Groves, M.; Hammer, B.; Hargus, C.; et al. The Atomic Simulation Environment-A Python Library for Working with Atoms. J. Phys. Condens. Matter 2017, 29 (273002), 1-30. https://doi.org/10.1088/1361-648X/aa680e.

(12) Kresse, G.; Furthmöller, J. Efficiency of Ab-Initio Total Energy Calculations for Metals and Semiconductors Using a Plane-Wave Basis Set. Comput. Mater. Sci. 1996, 6 (1), 15-50. https://doi.org/10.1016/0927-0256(96)00008-0.

(13) Pulay, P. Convergence Acceleration of Iterative Sequences. the Case of Scf Iteration. Chem. Phys. Lett. 1980, 73 (2), 393-398. https://doi.org/10.1016/0009-2614(80)80396-4.

(14) Blöchl, P. E. Projector Augmented-Wave Method. Phys. Rev. B 1994, 50 (24), 17953-17979. https://doi.org/10.1103/PhysRevB.50.17953.

(15) Perdew, J. P.; Burke, K.; Ernzerhof, M. Generalized Gradient Approximation Made Simple. Phys. Rev. Lett. 1996, 77 (18), 3865-3868. https://doi.org/10.1103/PhysRevLett.77.3865.

(16) Islam, M. S.; Fisher, C. A. J. Lithium and Sodium Battery Cathode Materials. Computational Insights into Voltage, Diffusion and Nanostructural Properties. Chem. Soc. Rev. 2014, 43 (1), 185-204. https://doi.org/10.1039/c3cs60199d.

(17) Meng, Y. S.; Arroyo-de Dompablo, M. E. First Principles Computational Materials Design for Energy Storage Materials in Lithium Ion Batteries. Energy Environ. Sci. 2009, 2 (6), 589. https://doi.org/10.1039/b901825e.

(18) Zhou, F.; Cococcioni, M.; Marianetti, C. A.; Morgan, D.; Ceder, G. First-Principles Prediction of Redox Potentials in Transition-Metal Compounds with LDA+U. Phys. Rev. B - Condens. Matter Mater. Phys. 2004, 70 (23), 1-8. https://doi.org/10.1103/PhysRevB.70.235121.

(19) Ong, S. P.; Chevrier, V. L.; Ceder, G. Comparison of Small Polaron Migration and Phase Separation in Olivine $\mathrm{LiMnPO}_{4}$ and $\mathrm{LiFePO}_{4}$ Using Hybrid Density Functional Theory. Phys. Rev. B 2011, 83 (7), 0751121-7. https://doi.org/10.1103/PhysRevB.83.075112.

(20) Johannes, M. D.; Hoang, K.; Allen, J. L.; Gaskell, K. Hole Polaron Formation and Migration in Olivine Phosphate Materials. Phys. Rev. B - Condens. Matter Mater. Phys. 2012, 85 (11), 115106. https://doi.org/10.1103/PhysRevB.85.115106.

(21) Anisimov, V. I.; Aryasetiawan, F.; Lichtenstein, I. First-Principles Calculations of the Electronic Structure and Spectra of Strongly Correlated Systems: The LDA $+U$ Method. J. Phys. Condens. Matter 1997, 9 (997), 767-808. https://doi.org/10.1088/0953-8984/9/4/002.

(22) Henkelman, G.; Arnaldsson, A.; Jónsson, H. A Fast and Robust Algorithm for Bader Decomposition of Charge Density. Comput. Mater. Sci. 2006, 36, 354-360. https://doi.org/10.1016/j.commatsci.2005.04.010. 
(23) Ouyang, C.; Shi, S.; Wang, Z.; Huang, X.; Chen, L. First-Principles Study of Li Ion Diffusion in LiFePO4. Phys. Rev. B - Condens. Matter Mater. Phys. 2004, 69 (10), 1-5. https://doi.org/10.1103/PhysRevB.69.104303.

(24) Kim, S.-W.; Kim, J.; Gwon, H.; Kang, K. Phase Stability Study of $\mathrm{Li}_{1-x} \mathrm{MnPO}_{4}(0 \leq x \leq 1)$ Cathode for Li Rechargeable Battery. J. Electrochem. Soc. 2009, 156 (8), A635. https://doi.org/10.1149/1.3138705.

(25) Perea, A.; Castro, L.; Aldon, L.; Stievano, L.; Dedryvère, R.; Gonbeau, D.; Tran, N.; Nuspl, G.; Bréger, J.; Tessier, C. Study of C-Coated $\mathrm{LiFe}_{0.33} \mathrm{Mn}_{0.67} \mathrm{PO}_{4}$ as Positive Electrode Material for Li-Ion Batteries. J. Solid State Chem. 2012, 192, 201-209. https://doi.org/10.1016/j.jssc.2012.04.016.

(26) Ding, B.; Xiao, P.; Ji, G.; Ma, Y.; Lu, L.; Lee, J. Y. High-Performance Lithium-Ion Cathode $\mathrm{LiMn}_{0.7} \mathrm{Fe}_{0.3} \mathrm{PO}_{4} / \mathrm{C}$ and the Mechanism of Performance Enhancements through Fe Substitution. ACS Appl. Mater. Interfaces 2013, 5 (22), 12120-12126. https://doi.org/10.1021/am403991f.

(27) Perea, A.; Sougrati, M. T.; Ionica-bousquet, C. M.; Fraisse, B.; Jumas, J. Operando ${ }^{57}$ Fe Mössbauer and XRD Investigation of $\mathrm{Li}_{x} \mathrm{Mn}_{y} \mathrm{Fe}_{1-y} \mathrm{PO}_{4} / \mathrm{C}$ Composites $(y=0.50 ; 0.75) .2012$, 9517-9524. https://doi.org/10.1039/c2ra20949g.

(28) Perea, A.; Sougrati, M. T.; Ionica-bousquet, C. M.; Fraisse, B.; Jumas, J. Operando ${ }^{57} \mathrm{Fe}$ Mössbauer and XRD Investigation of $\mathrm{Li}_{x} \mathrm{Mn}_{y} \mathrm{Fe}_{1-y} \mathrm{PO}_{4} / \mathrm{C}$ Composites $(y=0 ; 0.25)$. 2012, 2080 2086. https://doi.org/10.1039/c1ra00256b.

(29) Yamada, A.; Kudo, Y.; Liu, K.-Y. Reaction Mechanism of the Olivine-Type $\mathrm{Li}_{x}\left(\mathrm{Mn}_{0.6} \mathrm{Fe}_{0.4}\right) \mathrm{PO}_{4}$ $(0 \leq x \leq 1)$. J. Electrochem. Soc. 2001, 148 (7), A747. https://doi.org/10.1149/1.1375167.

(30) Bramnik, N. N.; Bramnik, K. G.; Nikolowski, K.; Hinterstein, M.; Baehtz, C.; Ehrenberg, H. Synchrotron Diffraction Study of Lithium Extraction from $\mathrm{LiMn}_{0.6} \mathrm{Fe}_{0.4} \mathrm{PO}_{4}$. Electrochem. SolidState Lett. 2005, 8 (8), A379. https://doi.org/10.1149/1.1940487.

(31) Chen, Y. C.; Chen, J. M.; Hsu, C. H.; Yeh, J. W.; Shih, H. C.; Chang, Y. S.; Sheu, H. S. Structure Studies on $\mathrm{LiMn}_{0.25} \mathrm{Fe}_{0.75} \mathrm{PO}_{4}$ by in-Situ Synchrotron X-Ray Diffraction Analysis. $J$. Power Sources 2009, 189 (1), 790-793. https://doi.org/10.1016/j.jpowsour.2008.07.088.

(32) Yamada, A.; Takei, Y.; Koizumi, H.; Sonoyama, N.; Kanno, R.; Itoh, K.; Yonemura, M.; Kamiyama, T. Electrochemical, Magnetic, and Structural Investigation of the $\mathrm{Li}_{x}\left(\mathrm{Mn}_{y} \mathrm{Fe}_{1-y}\right) \mathrm{PO}_{4}$ Olivine Phases. Chem. Mater. 2006, 18 (3), 804-813. https://doi.org/10.1021/cm051861f.

(33) Nam, K. W.; Yoon, W. S.; Zaghib, K.; Yoon Chung, K.; Yang, X. Q. The Phase Transition Behaviors of $\mathrm{Li}_{1-x} \mathrm{Mn}_{0.5} \mathrm{Fe}_{0.5} \mathrm{PO}_{4}$ during Lithium Extraction Studied by in Situ X-Ray Absorption and Diffraction Techniques. Electrochem. commun. 2009, 11 (10), 2023-2026. https://doi.org/10.1016/j.elecom.2009.08.044.

(34) Urban, A.; Lee, J.; Ceder, G. The Configurational Space of Rocksalt-Type Oxides for HighCapacity Lithium Battery Electrodes. Adv. Energy Mater. 2014, 4 (13), 1400478. https://doi.org/10.1002/aenm.201400478. 
(35) Trinh, N. D. Les Batteries Lithium-Ion À Haute Densité Énergétique: Nouvelle Formulation Et Caractérisation De Matériaux D'Insertion Substitués Pour L'Électrode Positive, Université du Québec à Montréal, dissertation, 2016.

(36) Snydacker, D. H.; Wolverton, C. Transition-Metal Mixing and Redox Potentials in $\operatorname{Li}_{\mathrm{x}}\left(\mathrm{M}_{1-\mathrm{y}}\right.$ $\left.\mathrm{M}_{\mathrm{y}}^{\prime}\right) \mathrm{PO}_{4}\left(\mathrm{M}, \mathrm{M}^{\prime}=\mathrm{Mn}, \mathrm{Fe}, \mathrm{Ni}\right)$ Olivine Materials from First-Principles Calculations. J. Phys. Chem. C 2016, 120 (11), 5932-5939. https://doi.org/10.1021/acs.jpcc.6b00575.

(37) Piper, L. F. J.; Quackenbush, N. F.; Sallis, S.; Scanlon, D. O.; Watson, G. W.; Nam, K.-W.; Yang, X.-Q.; Smith, K. E.; Omenya, F.; Chernova, N. A.; et al. Elucidating the Nature of Pseudo Jahn-Teller Distortions in Li x MnPO 4 : Combining Density Functional Theory with Soft and Hard X-Ray Spectroscopy. J. Phys. Chem. C 2013, 117 (20), 10383-10396. https://doi.org/10.1021/jp3122374.

(38) Norberg, N. S.; Kostecki, R. FTIR Spectroscopy of a $\mathrm{LiMnPO}_{4}$ Composite Cathode. Electrochim. Acta 2011, 56 (25), 9168-9171. https://doi.org/10.1016/j.electacta.2011.07.116.

(39) Freitag, R.; Conradie, J. Understanding the Jahn-Teller Effect in Octahedral Transition-Metal Complexes: A Molecular Orbital View of the $\mathrm{Mn}(\beta \text {-Diketonato })_{3}$ Complex. J. Chem. Educ. 2013, 90 (12), 1692-1696. https://doi.org/10.1021/ed400370p.

(40) Clément, R. J.; Bruce, P. G.; Grey, C. P. Review - Manganese-Based P2-Type Transition Metal Oxides as Sodium-Ion Battery Cathode Materials. J. Electrochem. Soc. 2015, 162 (14), A2589-A2604. https://doi.org/10.1149/2.0201514jes.

\section{TOC Graphic}

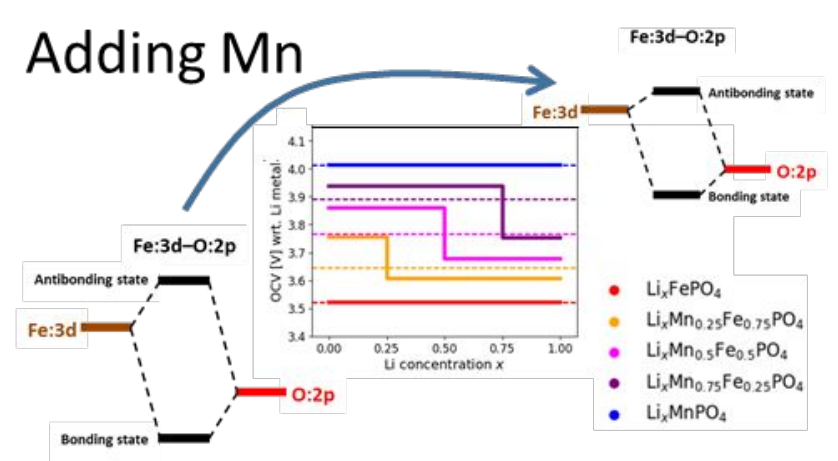


a) Phase-stability plots showing the relative energies and the convex hull using the lowest-lying energies with the associated open-circuit-voltage profiles for investigated ratios of Fe and Mn. b) Phase-stability plots showing the relative energies and the convex hull using the Boltzmann averaged $(T=300 \mathrm{~K})$ energies with the associated open-circuit-voltage profiles for investigated ratios of Fe and $\mathrm{Mn}$.

$181 \times 101 \mathrm{~mm}(150 \times 150 \mathrm{DPI})$ 


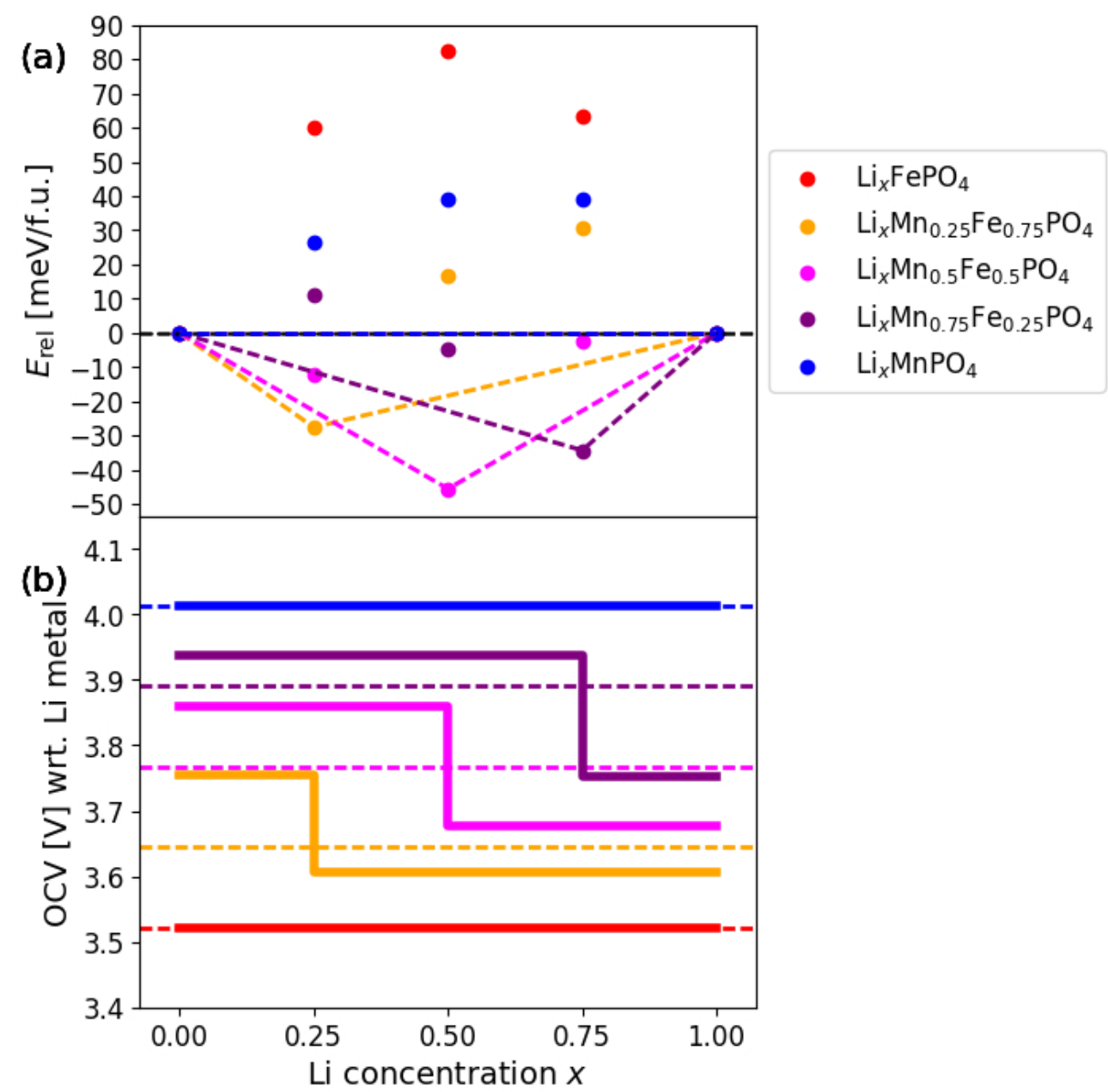

(a) Convex hulls, represented by dashed lines, of investigated ratios of Fe and Mn in E_(Li_x Mn_y Fe_(1-y) PO_4 ) and (b) the associated open-circuit voltage (OCV) showing how the redox couple plateaus increase upon Fe substitution by Mn. Equilibrium voltages are indicated by dashed horizontal lines.

$178 \times 176 \mathrm{~mm}(100 \times 100 \mathrm{DPI})$ 


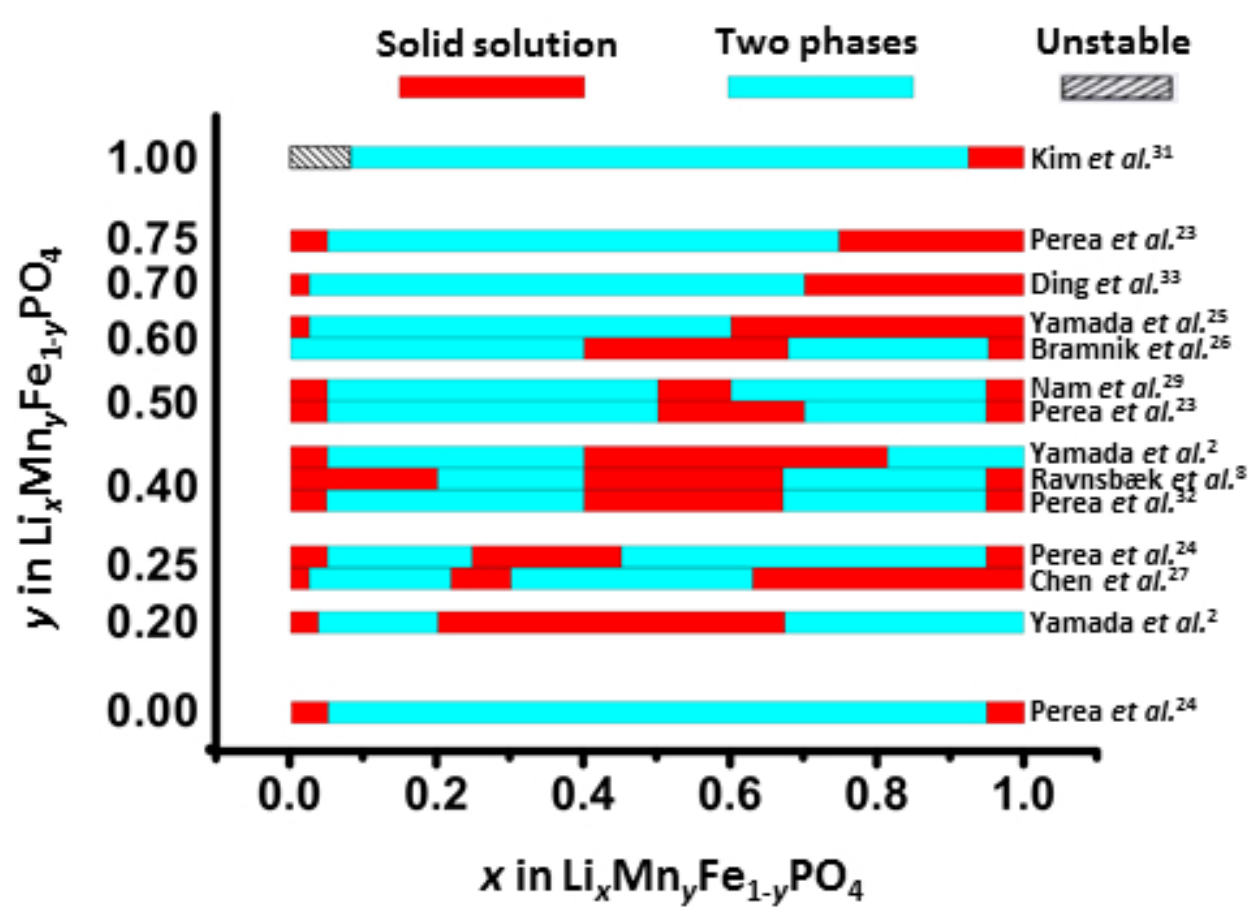

Figure 3. Overview of phases in $\mathrm{Li}_{x} \mathrm{Mn}_{y} \mathrm{Fe}_{1-y} \mathrm{PO}_{4}$ from previous experimental studies $2,8,31-33,23-30$. Adapted from Trinh ${ }^{34}$.

$125 \times 91 \mathrm{~mm}(96 \times 96 \mathrm{DPI})$ 


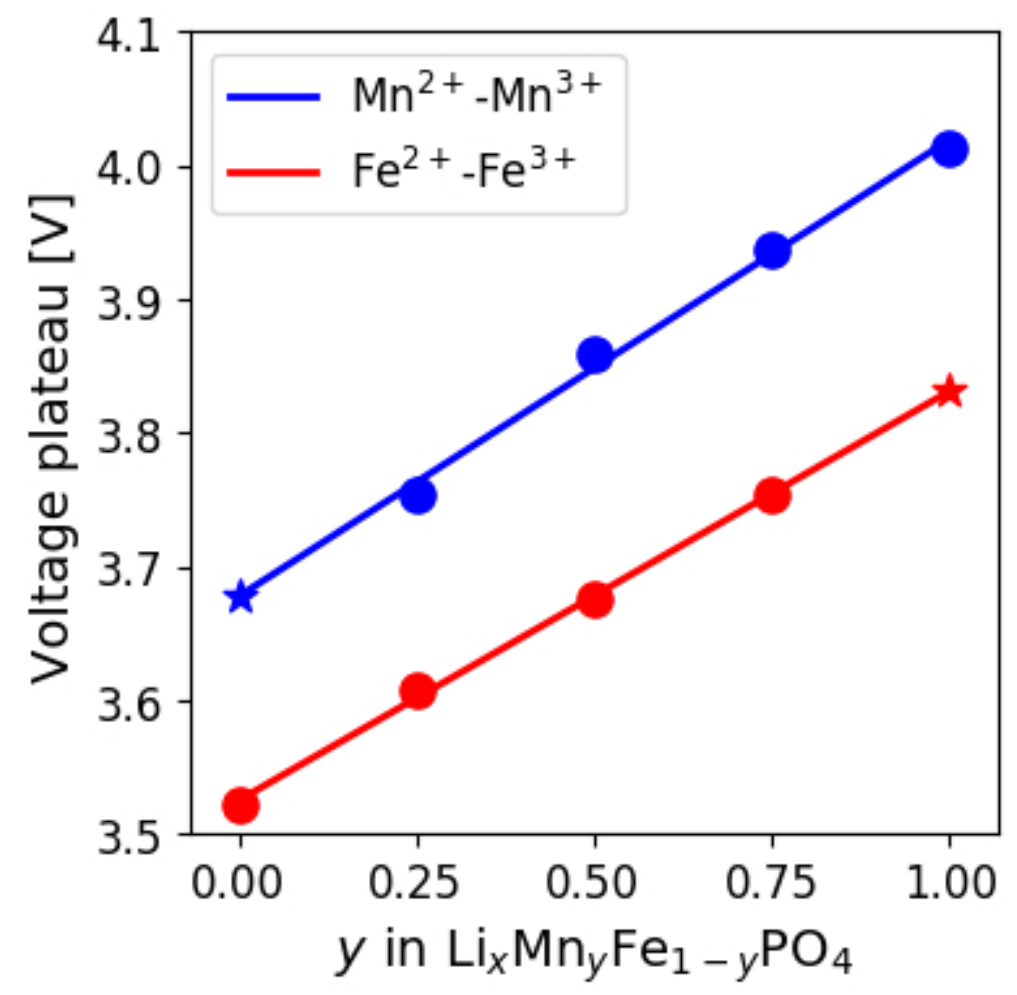

Figure 4. Calculated $\mathrm{TM}^{2+}-\mathrm{TM}^{3+}$ voltage plateau dependence on the $\mathrm{Mn}$ content $(y)$ in $\mathrm{Li}_{x} \mathrm{Mn}_{y} \mathrm{Fe}_{1-y} \mathrm{PO}_{4}$. The star points are extrapolated from the dot data points obtained from the voltage plateaus in Figure 2(b).

$100 \times 99 \mathrm{~mm}(100 \times 100 \mathrm{DPI})$ 


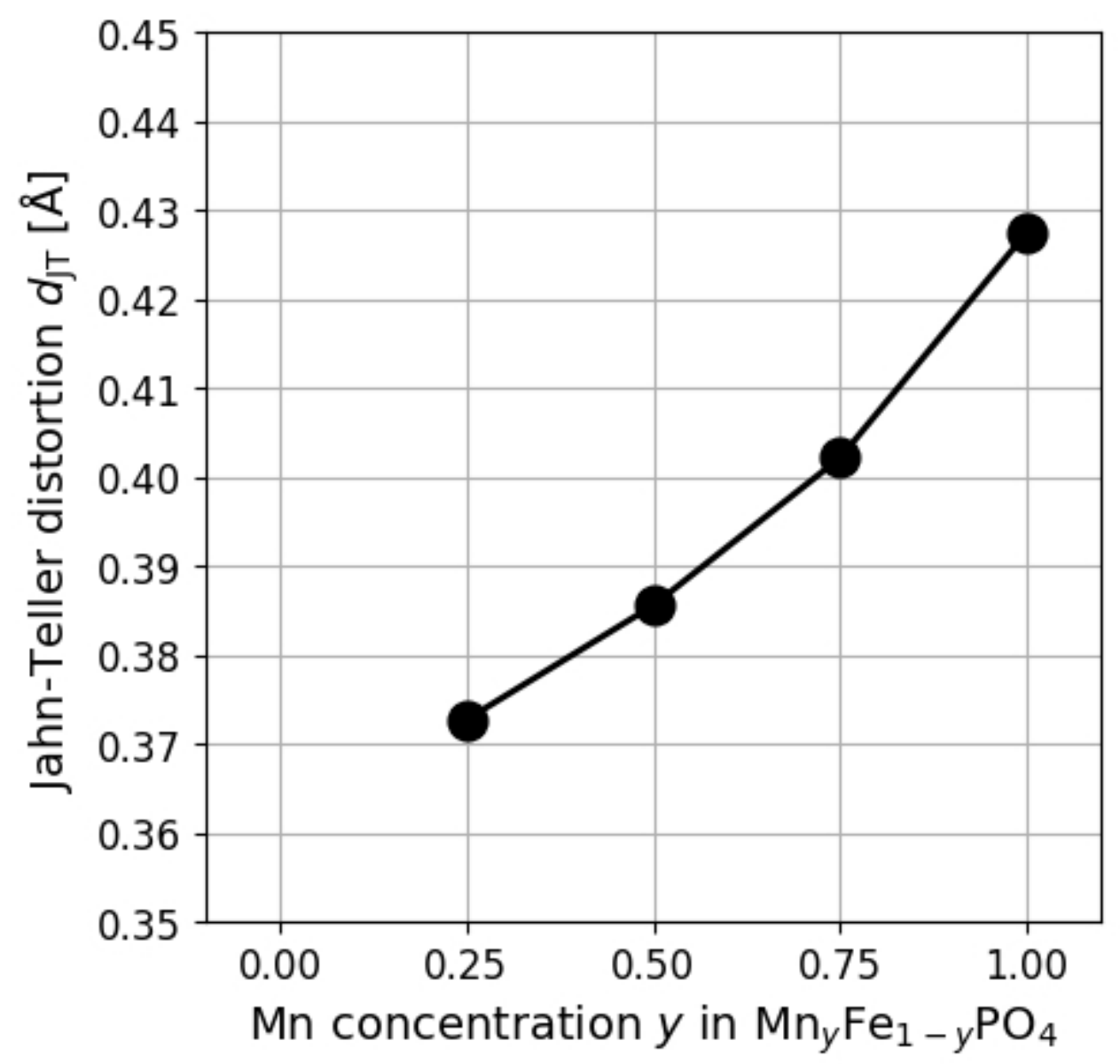

Figure 5. The average Jahn-Teller lattice distortion for each $\mathrm{Mn}$ concentration $y$ in $\mathrm{Mn}_{y} \mathrm{Fe}_{1-y} \mathrm{PO}_{4}$ configuration.

$124 \times 119 \mathrm{~mm}(100 \times 100 \mathrm{DPI})$ 


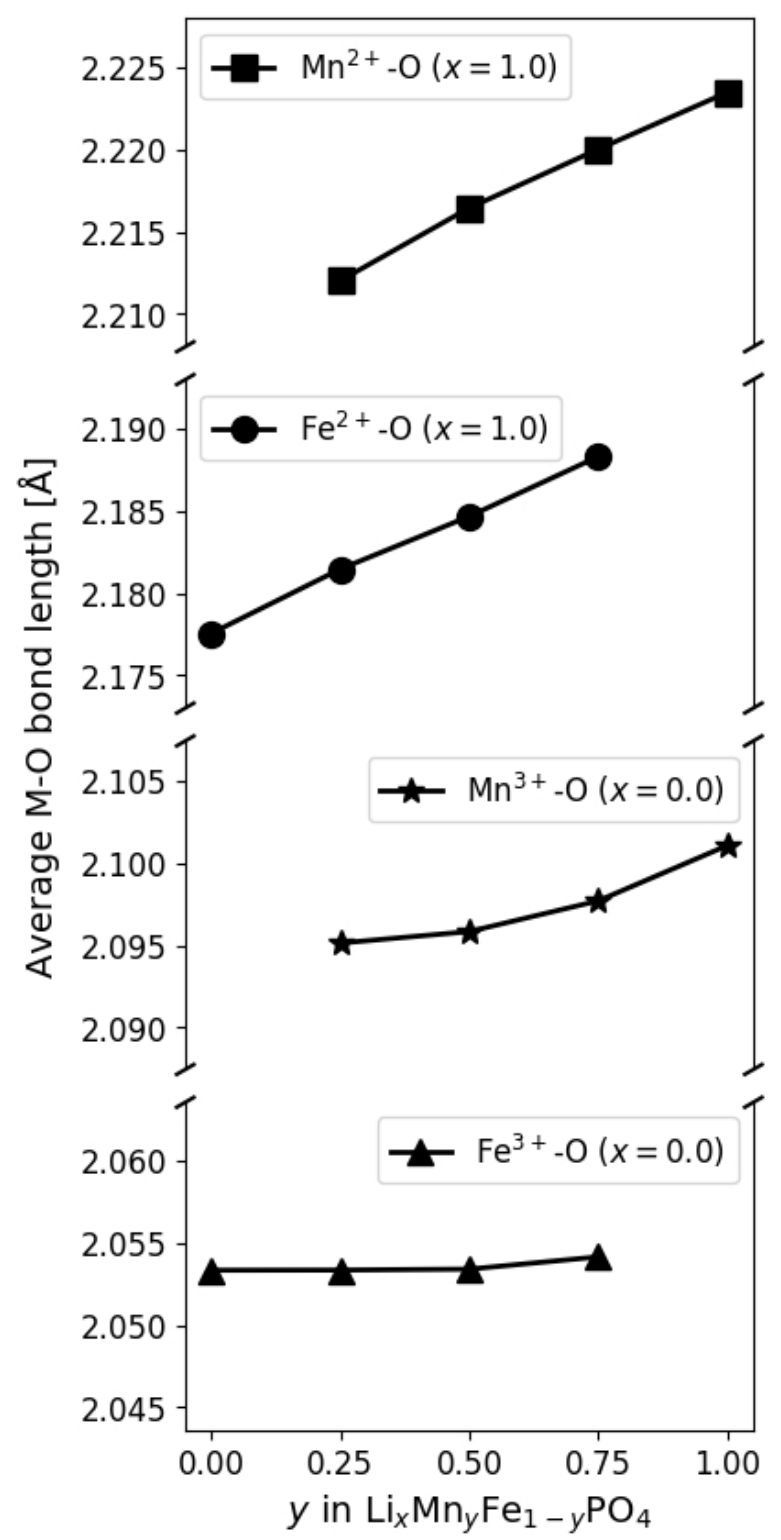

Figure 6. Average metal-oxygen bond lengths versus Mn concentration $y$ for both oxidation states ( $2+$ and $3+)$ of $\mathrm{Mn}$ and $\mathrm{Fe}$.

$107 \times 216 \mathrm{~mm}(100 \times 100 \mathrm{DPI})$ 


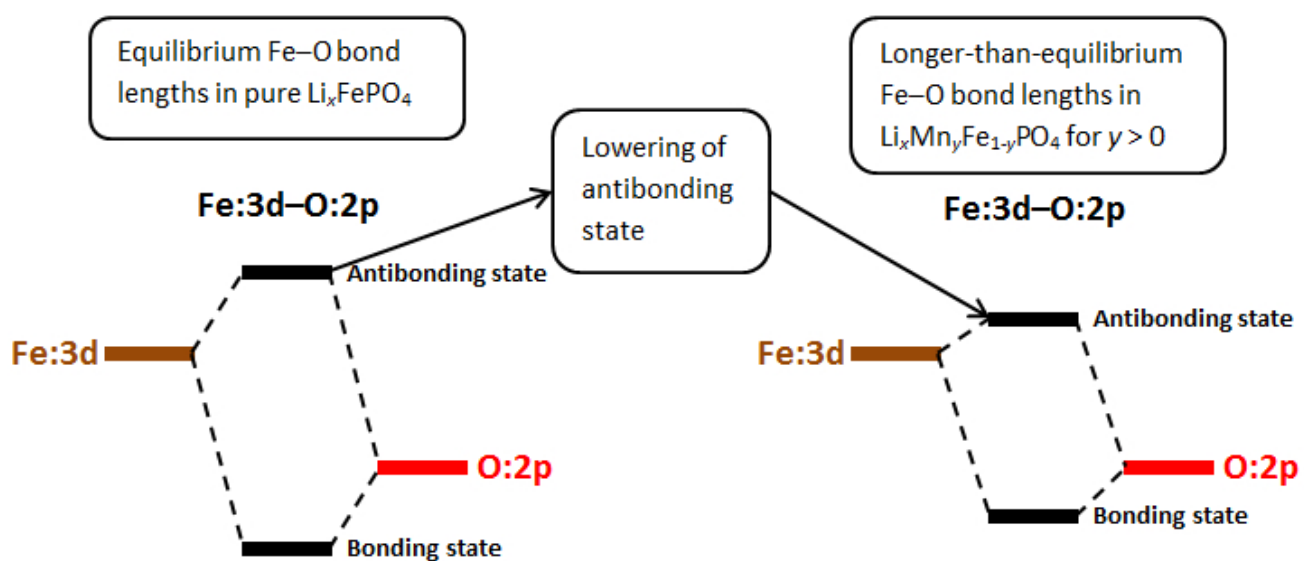

Figure 7. Origin of $\mathrm{Fe}^{2+}-\mathrm{Fe}^{3+}$ voltage-plateau upshift upon increasing $\mathrm{Mn}$ concentration: As $\mathrm{Fe}$ is substituted for $\mathrm{Mn}$, the $\mathrm{Fe}-\mathrm{O}$ bond lengths increase (ultimately by $0.014 \AA$ on average from our calculations), thereby weakening the Fe-O bonds. This lowers the antibonding state of the Fe:3d-O:2p mixing, lowering the redox potential and thereby increasing the OCV.

$152 \times 64 \mathrm{~mm}(120 \times 120$ DPI $)$ 


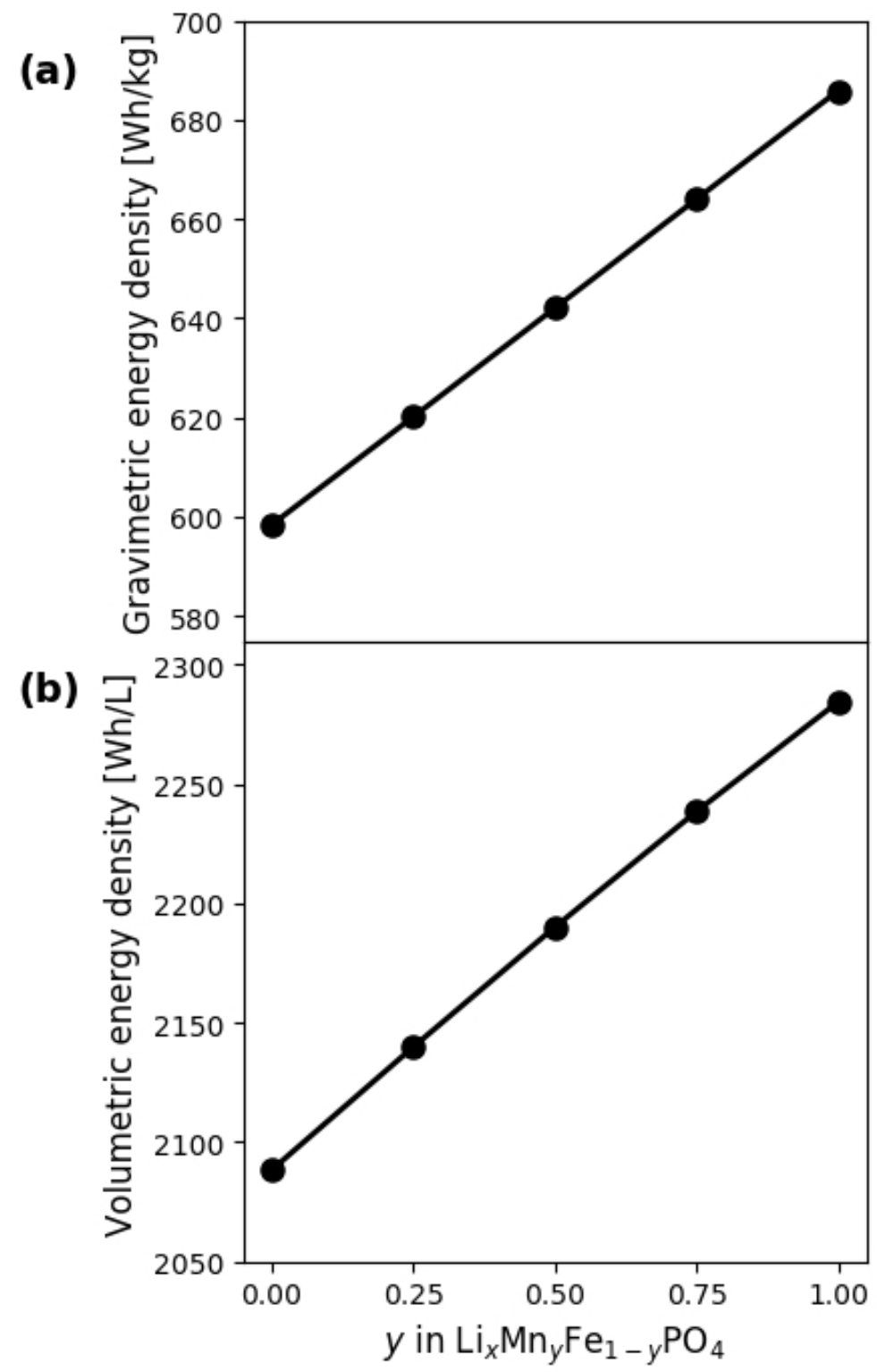

Figure 8. Gravimetric (a) and volumetric (b) energy densities versus the Mn content $y$. Both densities are for the active $\mathrm{Li}_{x} \mathrm{Mn}_{y} \mathrm{Fe}_{1-y} \mathrm{PO}_{4}$ material. The volumetric density is calculated using the volume of the fully lithiated unit cells.

$113 \times 176 \mathrm{~mm}(100 \times 100 \mathrm{DPI})$ 